\title{
Importance of background seasonality over the eastern equatorial Pacific in a coupled atmosphere-ocean response to westerly wind events
}

\author{
Michiya Hayashi $^{1,2}$ (1) $\cdot$ Masahiro Watanabe $^{1}$
}

Received: 17 March 2016 / Accepted: 29 November 2016 / Published online: 29 December 2016

(c) The Author(s) 2016. This article is published with open access at Springerlink.com

\begin{abstract}
Coupled atmosphere-ocean response to westerly wind events (WWEs), which sometimes trigger El Niños, was investigated using a coupled general circulation model to clarify its dependence on the timing and location of WWEs. Twelve sets of 20-member ensembles were made with an idealized single WWE imposed in different months from January to July and at different longitudes from $160^{\circ} \mathrm{E}$ to $160^{\circ} \mathrm{W}$. The initial ocean states are set to be near neutral to El Niño/La Niña so that the lagged response to WWEs can be isolated. The results show that sea surface temperature (SST) in the Niño3.4 region increases largely and persistently favorable for El Niño growth when a WWE is imposed in May, whereas a WWE in March increases SST only in the easternmost Pacific. In both cases, an oceanic Kelvin wave propagates eastward to warm the eastern Pacific. When forced by the WWE in May, a positive Niño3.4 SST anomaly appears in boreal summer according to the seasonal outcrop of the equatorial thermocline, and it can strongly interact with seasonally active tropical rain
\end{abstract}

This paper is a contribution to the special collection on ENSO Diversity. The special collection aims at improving understanding of the origin, evolution, and impacts of ENSO events that differ in amplitude and spatial patterns, in both observational and modeling contexts, and in the current as well as future climate scenarios. This special collection is coordinated by Antonietta Capotondi, Eric Guilyardi, Ben Kirtman and Sang-Wook Yeh.

Michiya Hayashi

michiyah@hawaii.edu

1 Atmosphere and Ocean Research Institute, University of Tokyo, 5-1-5 Kashiwanoha, Kashiwa, Chiba 277-8568, Japan

2 Present Address: Department of Atmospheric Sciences, SOEST, University of Hawai'i at Mānoa, 2525 Correa Rd., HIG350, Honolulu, HI 96822, USA belt to amplify the SST response further. A favorable combination of timing and location that maximize the impact of WWEs on El Niños in the subsequent winter is suggested albeit its relevance to nature should severely be tested. Another experiment with initial ocean states in El Niño/La Niña years showed that the WWEs in May are efficient to amplify El Niño similar to the neutral case, but are not efficient to suppress La Niña.

Keywords Westerly wind event $\cdot$ Coupled atmosphereocean response $\cdot$ Annual cycle $\cdot$ Coupled general circulation model $\cdot$ El Niño-Southern oscillation

\section{Introduction}

Strong equatorial westerly winds that persist for several days to weeks over the western-central Pacific are called westerly wind events (WWEs). Various atmospheric phenomena such as the Madden-Julian oscillation (MJO), tropical cyclones, and cold surges are thought to cause WWEs stochastically (Luther et al. 1983; Hartten 1996; Harrison and Vecchi 1997; Vecchi and Harrison 2000) or state dependently (Eisenman et al. 2005; Seiki and Takayabu 2007a, b; Puy et al. 2015; Hayashi and Watanabe 2016). Despite their short duration, WWEs are important elements to the tropical climate variability as they sometimes trigger El Niño events (Wyrtki 1975; McPhaden 1999; McPhaden and Yu 1999). Interaction of interannual variability with WWEs is suggested to cause diversity in the El NiñoSouthern Oscillation (ENSO) (Lengaigne et al. 2004; Perez et al. 2005; Eisenman et al. 2005; Jin et al. 2007; Gebbie et al. 2007; Lopez et al. 2013; Hu et al. 2014; Chen et al. 2015). 
WWEs can excite oceanic downwelling Kelvin waves. They act to expand the edge of the western Pacific warm pool eastward and induce sequential WWEs, resulting in a further eastward shift of a large-scale convection over the western Pacific, and potentially contribute to the El Niño development (Latif et al. 1988; Lengaigne et al. 2002, 2003, 2004; Eisenman et al. 2005; Vecchi et al. 2006; Hendon et al. 2007; Drushka et al. 2014; Fedorov et al. 2015). A typical example is the $1997 / 98 \mathrm{El}$ Niño event, when the eastern Pacific SST rapidly increased after the sequential occurrence of WWEs from late-1996 to mid-1997. However, El Niño growth did not follow two strong WWEs that occurred from January to March in 2014 (McPhaden et al. 2015). Menkes et al. (2014) suggested that subsequent WWEs were required for El Niño to start growing. A similar situation was observed in 1974/1975, when warming occurred only in the easternmost Pacific (McPhaden et al. 2015). Thus, the coupled response to WWEs may be different from each other.

Oceanic variation observed in the eastern Pacific associated with the WWEs was examined by Vecchi and Harrison (2000). Using observational data for 1986-1998, they composited the SST anomaly (SSTA) related with WWEs. On the whole, warming was observed in the central and eastern Pacific relative to a composite SSTA without any WWEs. In the WWE region the west of the dateline, the sea surface was cooled, whereas it was warmed in the east, implying a dependency of the oceanic response on the longitudinal location of WWEs (see also, Chiodi et al. 2014). The oceanic response to WWEs may also depend on the seasons, according to several ocean model studies. In a simple advective model, WWE-induced anomalous eastward currents between February and April were not efficient to warm SST in the equatorial Pacific but caused coastal warming due to the seasonality of zonal SST gradient (Harrison and Schopf 1984). It was also suggested that the warming caused by WWE-induced Kelvin waves occurs most efficiently when the easterly trade winds are strongest via the modulation of tropical instability waves (TIWs) in an ocean general circulation model (Harrison and Giese 1988; Giese and Harrison 1991), although such TIW response to WWEs lacks consensus in observations (Qiao and Weisberg 1995). In nature, however, the atmospheric state responding to SSTAs consequently influences the oceanic state (e.g., Lengaigne et al. 2004). Therefore, it is reasonable to discuss the response to WWEs in a coupled atmosphere-ocean system, not only the oceanic responses.

The response of a coupled general circulation model (CGCM) to a single WWE forcing imposed in January was examined by Latif et al. (1988), indicating the importance of the interaction with the Walker circulation to warm the equatorial Pacific SST persistently. They conducted the same experiment again, except for imposing the WWE in
July. However, no clear difference was observed between the two experiments. This insensitivity to the seasons was attributed to the fact that the atmospheric model used did not realistically reproduce the seasonal march of tropical rain belt. In a simple linear CGCM on an equatorial $\beta$ plane, a coupled response to WWE was highly sensitive to the strength of trade winds and thermocline depth in background states (Fedorov 2002; Fedorov et al. 2003). Although WWE occurring 6 to 10 months prior to the peak of El Niño was suggested to strengthen El Niño significantly (Fedorov 2002), the assumption of meridional symmetry is not valid when considering the seasonal march of the background precipitation (e.g., Horel 1982).

In this study, the coupled atmosphere-ocean response to an idealized WWE is examined by using a state-of-theart CGCM to clarify the relationship between the response to WWE and background seasonality in both the atmosphere and ocean. To extract the response isolated from the ENSO cycle, we adopt an ENSO-neutral ocean initial state. The impact of a WWE on the ENSO cycle is further discussed with another experiment using the initial ocean state including ENSO perturbations.

The rest of this paper is structured as follows. The experimental designs, data sets, and annual cycle in the model are described in Sect. 2. In Sect. 3, we show the various response of the coupled system to WWEs. Section 4 shows the process of WWE-induced coupled response and its generality. Their impacts on the ENSO cycle are discussed in Sect. 5. The implication to the real ENSO cycle is discussed in Sect. 6, and conclusions are given in Sect. 7.

\section{Method and data}

\subsection{Model}

An updated version of the Model for Interdisciplinary Research on Climate version 5 (MIROC5, Watanabe et al. 2010) is used for all the experiments. The modification from the original version is mainly in the ocean component model, which has replaced the horizontal coordinates with a tripolar grid having finer vertical resolution (see the supplementary information of Watanabe et al. 2014). For the ocean component model over the tropics, the zonal resolution is fixed as $1^{\circ}$ longitude, whereas the meridional and vertical resolutions become finer toward the equator and the surface with $63 \mathrm{lev}$ els, and the meridional resolution is around $0.5^{\circ}$ latitude. For ease of analysis, the model outputs are interpolated onto a $1^{\circ}$ grid in the zonal and meridional directions. The atmospheric model is the same as MIROC5, having a spatial resolution of T85 with 40 vertical levels up to $3 \mathrm{hPa}$. The radiative forcing and other boundary conditions follow the Coupled Model Intercomparison Project phase 5 (CMIP5; Taylor et al. 2012) 
Representative Concentration Pathways 4.5 (RCP4.5) scenario, and values after January 1, 2014, are used. This radiative forcing reduces a cold SST bias at the equatorial Pacific compared to a pre-industrial control run. The integration period for each experiment is 18 months starting on January 1 , until June 30 of the following year. The number of ensemble members in each experiment is 20 .

To determine the initial values for the experiments, we conducted a centennial run from 1850 with the radiative forcing and other boundary conditions following CMIP5 historical and RCP4.5 scenario runs before and after 2006, respectively (referred to as the "historical run"). Whereas the climatological mean states for 1981-2010 are used for the initial states of the atmosphere and land, the ocean initial state is made by averaging randomly chosen 29 out of 30 years. That is, the ocean initial values are near-neutral with respect to the ENSO cycle, but include small perturbations in each ensemble member. Initial values for El Niño and La Niña years are also used to examine the impact of WWEs on the ENSO cycle in Sect. 5.

In our numerical experiments, zonal wind stress on the ocean $\left(\tau_{x}\right.$, unit: $\left.\mathrm{N} \mathrm{m}^{-2}\right)$ is replaced as

$\tau_{x}=\tau_{x}^{\text {model }}+\tau_{x}^{W W E}$,

where $\tau_{x}^{\text {model }}$ is calculated in the model, and $\tau_{x}^{W W E}$ is imposed as a dynamical WWE forcing. $\tau_{x}^{W W E}$ has the longitude $(x)$, latitude $(y)$, and time $(t)$ dimensions as the following form:

$\tau_{x}^{W W E} \equiv 0.2 F(x, y, t) \exp \left\{-\frac{\left(x-x_{0}\right)^{2}}{\left(20^{\circ}\right)^{2}}-\frac{y^{2}}{\left(5^{\circ}\right)^{2}}\right\}$.

A stepwise function $F$ indicates that $F(x, y, t)=1$ if $\quad x_{0}-20^{\circ} \leq x \leq x_{0}+20^{\circ}, \quad-5^{\circ} \leq y \leq 5^{\circ}, \quad$ and $t_{0}-6 \leq t \leq t_{0}+6$ [day], otherwise $F=0$. Figure 1a shows the structure of the imposed WWE, approximately following the composite structure of the observed WWEs in Fig. 17 (see Appendix). The maximum magnitude of $\tau_{x}^{W W E}$ averaged between $5^{\circ} \mathrm{S}$ and $5^{\circ} \mathrm{N}$ is about $0.14 \mathrm{~N} \mathrm{~m}^{-2}$ (Fig. 1b), assuming strong events. The other parameters in Eq. (2) are the center longitude $\left(x_{0}\right)$ and center date $\left(t_{0}\right)$ of the imposed WWE; we set $x_{0}$ at $160^{\circ} \mathrm{E}, 180^{\circ}$, and $160^{\circ} \mathrm{W}$ to capture various locations over the Pacific with $t_{0}$ set to the 15th of January, March, May, and July, assuming the typical season of El Niño onsets. In this way, we conduct 12 sets of ensemble experiments in addition to a reference experiment without the imposed WWE (referred to as REF). The names of these experiments are summarized in Table 1. Since the WWE occurrence is concentrated over the western Pacific (Fig. 16 in Appendix), we focus on WWE-160E experiments. Note that $\tau_{x}^{W W E}$ is set to zero where the grid overlaps land in the model; the area is very limited and does not affect the results.

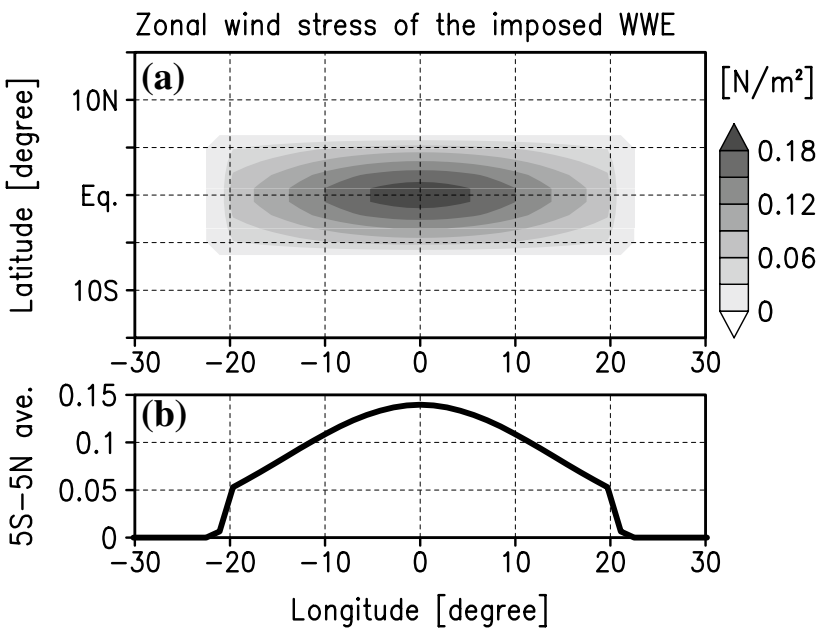

Fig. 1 a Horizontal structure of the eastward zonal wind stress [unit: $\mathrm{N} \mathrm{m}^{-2}$ ] of the imposed WWE and $\mathbf{b}$ its average between $5^{\circ} \mathrm{S}$ and $5^{\circ} \mathrm{N}$

The background climatology is defined as the average of REF each day, and hereafter, an anomaly is defined by the difference between the climatology and each ensemble member of the experiments forced by the WWE. The difference of anomalous fields between each experiment and REF having the same initial values is called "WWE contribution." The statistical significance of its ensemble mean is tested by Welch's t-test.

\subsection{Observational data}

To confirm how the background seasonality is similar to observations, we use two observation-based monthly data sets. Ocean temperature data are derived from Ishii and Kimoto (2009). GPCP precipitation data are also used (available at http://www.esrl.noaa.gov/psd/) (Adler et al. 2003). The horizontal resolutions of these two data sets are $1^{\circ}$ and $2.5^{\circ}$, respectively, and the base period for deriving the climatological monthly values is $1981-2010$.

\subsection{Model climatology}

Figures 2 and 3 compare annual cycles between the observations and model. The model reproduces the seasonal intensification of the eastern Pacific cold tongue, represented by $24{ }^{\circ} \mathrm{C}$ SST isotherms (Fig. 2a, b), although it extends too far to the west than the observation. The model may overrepresent the eastern edge of the western Pacific warm pool migrating to the west after June (Fig. 2a, b). Figure $2 \mathrm{c}$, d show the annual cycles of the climatological precipitation averaged over $170^{\circ}-120^{\circ} \mathrm{W}$. Albeit the larger amplitude, the annual cycle associated with the intertropical convergence zone (ITCZ) at the eastern Pacific is well represented in the model. Remarkably, there is no "double 
Table 1 List of the names of experiments (left column), and the centers of month (middle column) and longitude (right column) for the imposed WWE in each experiment

\begin{tabular}{lll}
\hline Experiment name & Month & Longitude \\
\hline REF & (No WWE) & \\
WWE1-160E & January & $160^{\circ} \mathrm{E}$ \\
WWE1-180 & January & $180^{\circ}$ \\
WWE1-160W & January & $160^{\circ} \mathrm{W}$ \\
WWE3-160E & March & $160^{\circ} \mathrm{E}$ \\
WWE3-180 & March & $180^{\circ}$ \\
WWE3-160W & March & $160^{\circ} \mathrm{W}$ \\
WWE5-160E & May & $160^{\circ} \mathrm{E}$ \\
WWE5-180 & May & $180^{\circ}$ \\
WWE5-160W & May & $160^{\circ} \mathrm{W}$ \\
WWE7-160E & July & $160^{\circ} \mathrm{E}$ \\
WWE7-180 & July & $180^{\circ}$ \\
WWE7-160W & July & $160^{\circ} \mathrm{W}$ \\
\hline
\end{tabular}

ITCZ" problem, a common atmospheric bias in CGCMs to have spurious precipitation maximum in the southeastern Pacific (Zhang et al. 2015).
Figure 3 shows the vertical structures of the ocean temperature averaged for the first and second halves of the year along the equator. The thermocline, represented by isotherms of $20-24{ }^{\circ} \mathrm{C}$, deepens from January to June and shoals after July in the eastern Pacific in both the observation and model. The main error occurs in the western Pacific, where the warm water is shifted to the west during the second half year in the model. The diffuse thermocline in the ocean model is a common bias in conventional ocean models (Tatebe and Hasumi 2010).

The model captures annual cycle of the ocean temperature and precipitation realistically, except for the fine structure of background rainfall (see Sect. 6) and the error in the western Pacific warm pool associated with a bias in the easterly trade wind stronger than observations (cf. Zhang and Sun 2014). The latter may cause the less frequent WWEs over the central Pacific in the model (Fig. 16b in Appendix). Nevertheless, in the historical run, the model is able to produce moderate ENSO events and extreme El Niños, accompanied by sequential WWEs similar to 1997/98 El Niño (cf. Sect. 5).
Fig. 2 Annual cycles of SST of the $\mathbf{a}$ observation and $\mathbf{b}$ model along the equator $\left(2^{\circ} \mathrm{S}-2^{\circ} \mathrm{N}\right)$ [unit: ${ }^{\circ} \mathrm{C}$ ] and climatological precipitation of the $\mathbf{c}$ observation and $\mathbf{d}$ model averaged over the eastern Pacific $\left(170^{\circ}-120^{\circ} \mathrm{W}\right)$ [unit: $\mathrm{mm} \mathrm{day}^{-1}$ ]. Dashed lines in $\mathbf{a}$ and $\mathbf{b}$ indicate 24 and $28{ }^{\circ} \mathrm{C}$ SST isotherms (a) SST Obs.

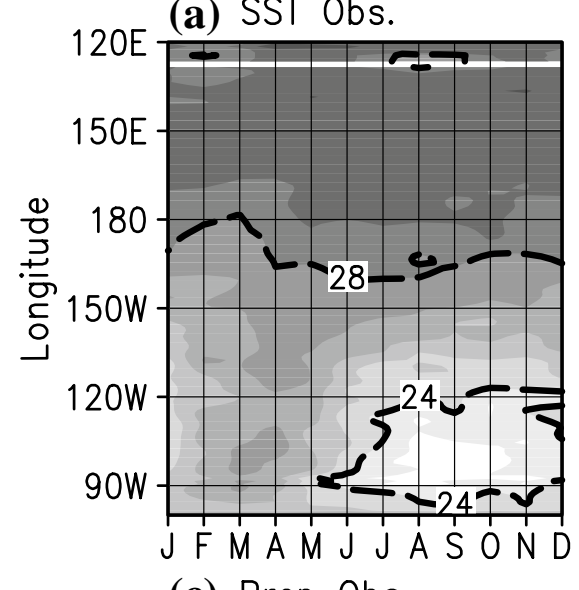

(c) Prcp Obs.

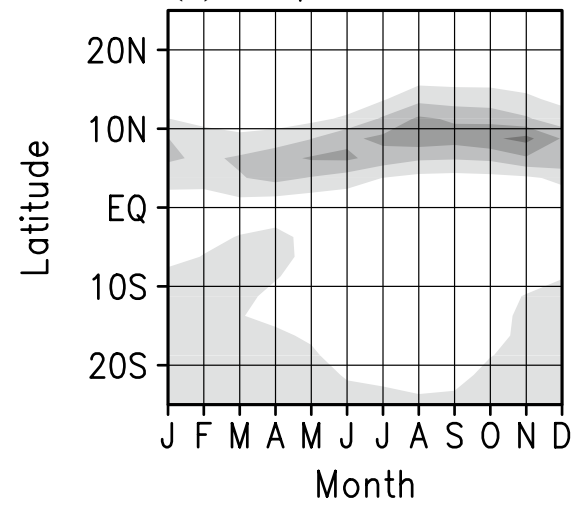

(b) SST Model

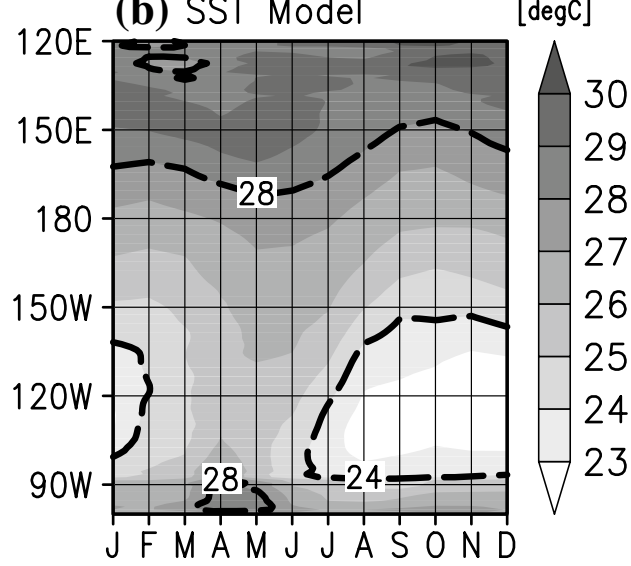

(d) Prcp Model

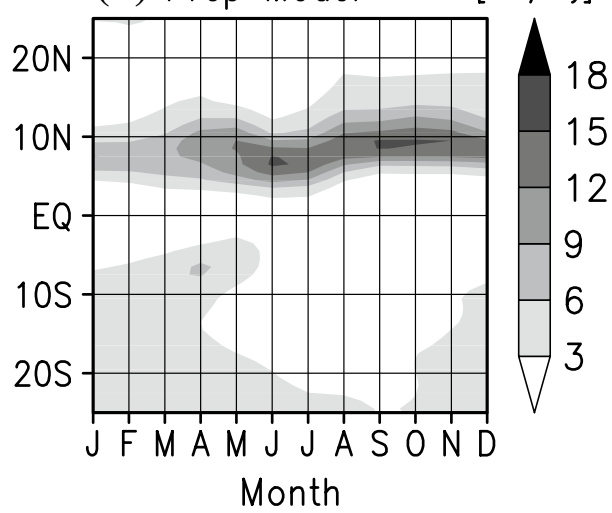


Fig. 3 Climatology of ocean temperature of the a observation and $\mathbf{b}$ model along the equator $\left(2^{\circ} \mathrm{S}-2^{\circ} \mathrm{N}\right)$ averaged from January to June (gray) and from July to December (black). From upper depths, the contours indicate isotherms of $28,24,22$, and $20{ }^{\circ} \mathrm{C}$

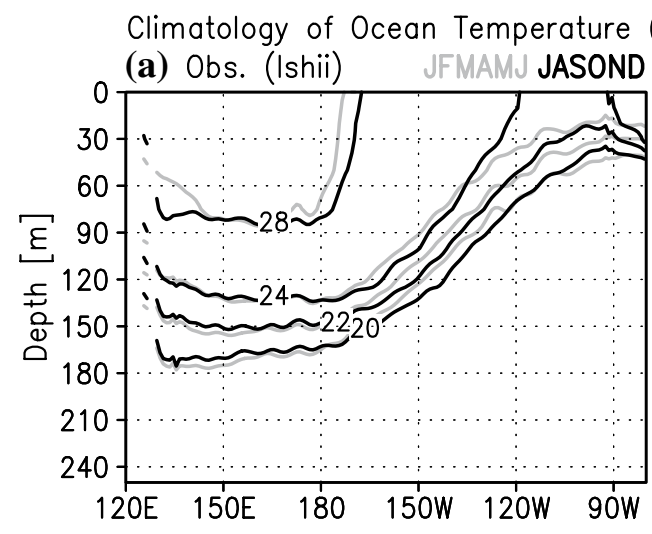

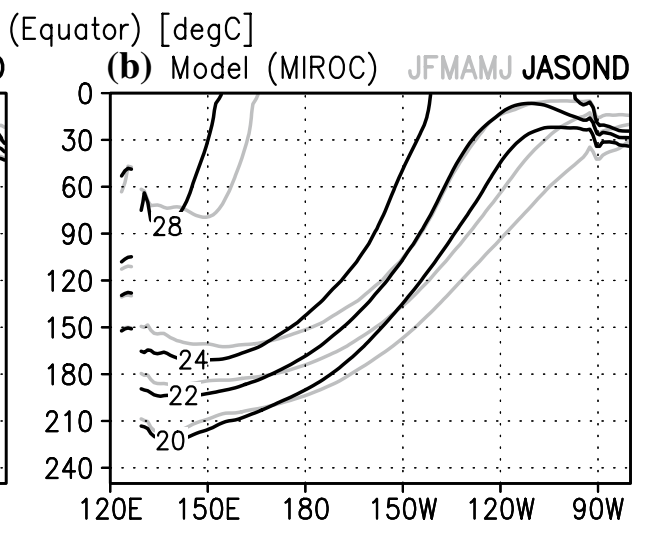

\section{WWE contributions}

\subsection{WWE contribution to Niño indices}

WWE contributions to Niño indices are examined using the monthly SSTA. Figure 4 shows the SSTAs at the Niño3.4 $\left(170^{\circ}-120^{\circ} \mathrm{W}, 5^{\circ} \mathrm{S}-5^{\circ} \mathrm{N}\right)$ and Niño $1+2\left(90^{\circ}-80^{\circ} \mathrm{W}, 10^{\circ} \mathrm{S}-0^{\circ}\right)$ regions for WWE-160E experiments. In all the experiments, the WWEs commonly warm the regions, but the duration is considerably different among the experiments.

WWE5-160E shows a warming of Niño3.4 SST that persists for more than 5 months with a peak of about 0.5 $\mathrm{K}$ in August. Although Niño3.4 SSTA similarly increases in the WWE1-160E and WWE7-160E, it decays rapidly. In (a) Nino3.4 SSTA
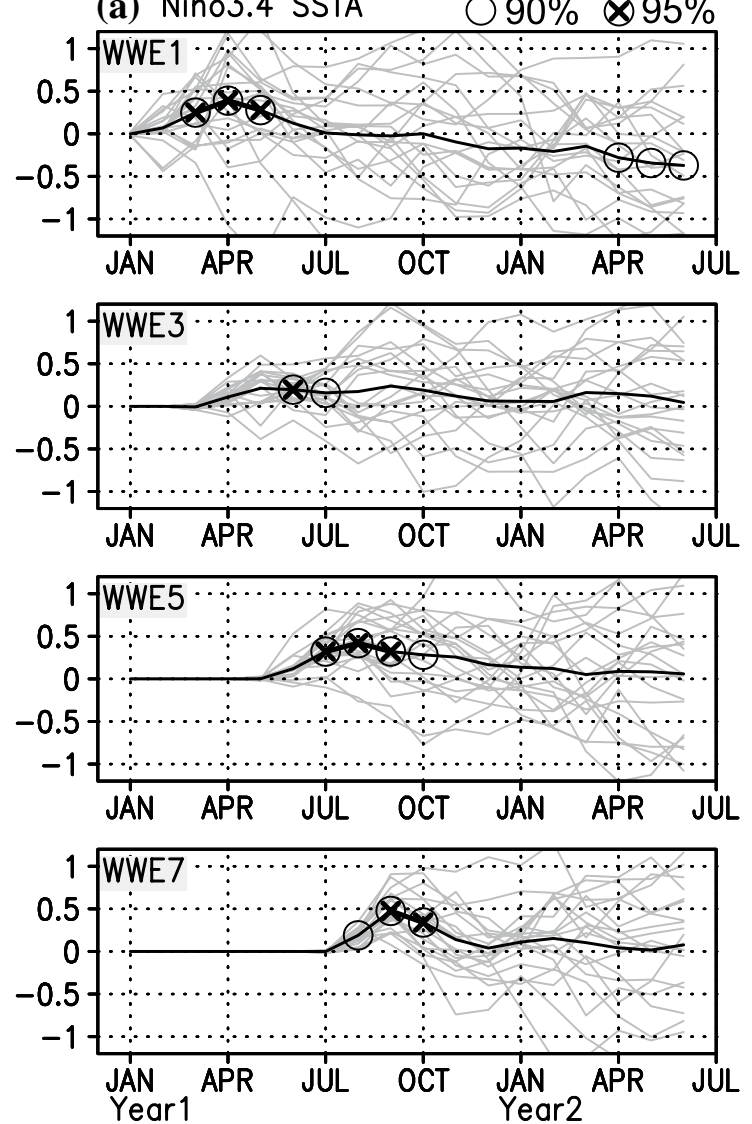

Fig. 4 WWE contributions of a Niño3.4 and b Niño1+2 monthly SSTAs [unit: K] for WWE-160E experiments. Black solid lines indicate ensemble means and thin-gray lines indicate each members. (b) Nino1+2 SSTA
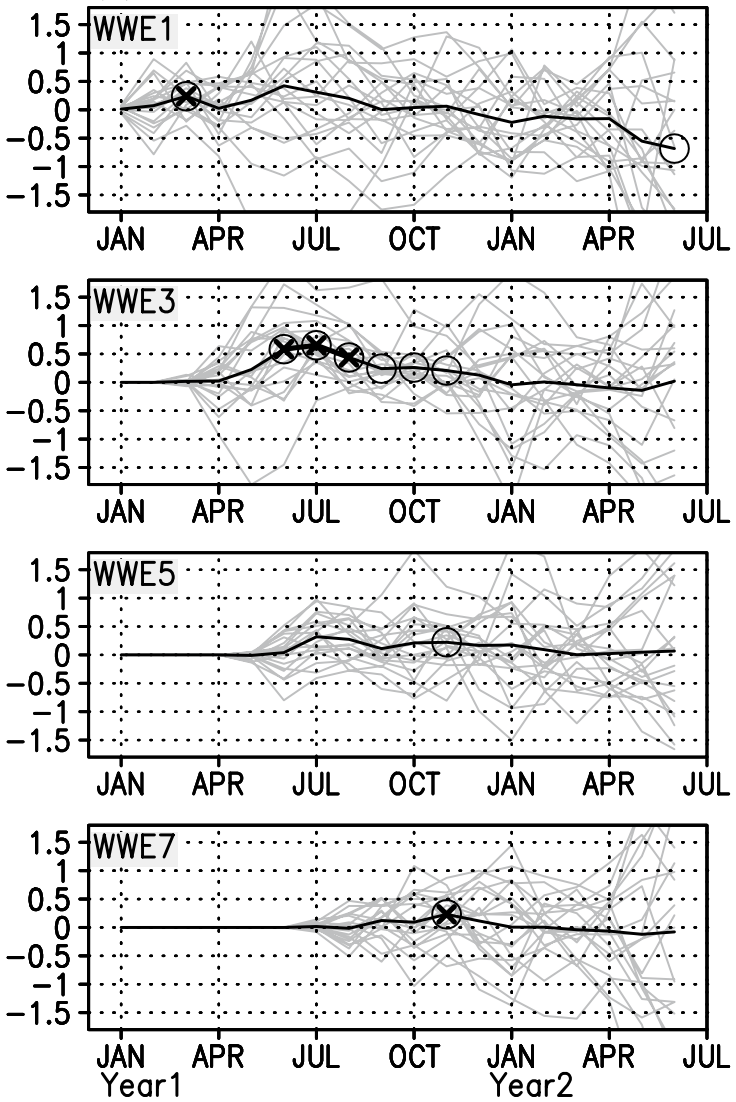

From top to bottom, the WWE is imposed in January, March, May, and July. The crossed and open circles indicate the 95 and $90 \%$ significant values by Welch's t-test, respectively 
Table 2 T-values (p-values) of the difference in the a Nino3.4 and b Nino1+2 SSTAs among the WWE1-, 3-, 5-, and 7-160E experiments

\begin{tabular}{cllll}
\hline (a) Niño3.4 SST & & & & \\
\hline & WWE1 & WWE3 & WWE5 & WWE7 \\
WWE1 & - & $-1.00(0.329)$ & $+0.33(0.745)$ & $+1.17(0.257)$ \\
WWE3 & $+1.00(0.329)$ & - & - & $+0.10(0.921)$ \\
WWE5 & $-0.33(0.745)$ & $-1.17(0.257)$ & $+1.03(0.316)$ \\
WWE7 & $-0.10(0.921)$ & $-1.03(0.316)$ & & $-0.23(0.821)$ \\
\hline (b) Niño1+2 SST & & & WWE5 & - \\
\hline & WWE1 & WWE3 & $+0.54(0.596)$ & WWE7 \\
WWE1 & - & $+1.70(0.105)$ & $-1.12(0.277)$ & $-1.77(0.093)$ \\
WWE3 & $-1.70(0.105)$ & - & - & $-0.56(0.582)$ \\
WWE5 & $-0.54(0.596)$ & $+1.12(0.277)$ & $+0.56(0.582)$ & - \\
WWE7 & $-0.04(0.969)$ & $+1.77(0.093)$ & & $+0.04(0.969)$ \\
\hline
\end{tabular}

All the values are averaged for 2-4 months after a WWE forcing in each experiment (e.g., from July to September for WWE5-160E). The Student's t-test was used

WWE3-160E, the Niño3.4 warming persists until July but much weaker amplitude of $0.2 \mathrm{~K}$, and the ensemble spread becomes large afterwards. Thus, WWE in May is more favorable to increase Niño3.4 SST.

The Niño1+2 SSTA is shown in Fig. 4b. In WWE3$160 \mathrm{E}$, the warming in Niño1+2 has a significant peak in July and continues for several months. In other experiments, the WWE contributions are not identified well. Thus, WWE in March is the most efficient to increase Niño1+2 SST.

The extent to which the difference in the ensemble means of the Niño3.4 and Niño1+2 SSTAs among the WWE-160E experiments is statistically significant was also examined using the Student's t-test (Table 2). Here, all the values are averaged for 2-4 months after a WWE forcing in each experiment. Table $2 \mathrm{a}$ indicates that WWEs in March (May) are inefficient (efficient) to increase the Niño3.4 SST, consistent with Fig. 4. In particular, the difference between WWE3 and WWE5 is highly significant with the p-value of 0.257. Also, the increase in the Niño1+2 SST due to WWEs in March is significant compared with the other experiments (Table 2b).

\subsection{WWE contribution to spatio-temporal structures}

The difference in the WWE contributions among the experiments is clear not only for the Niño indices but also for the spatial structure of the coupled response. Figure 5 summarizes the response in WWE5-160E, in which the Niño3.4 SSTA increased the most compared to other experiments. Here, "day $N$ " in the figure corresponds to $N$ th day since the center date of the imposed WWE period (i.e., 15th May for WWE5-160E).

The vertical structure of the ocean temperature along the equator shows that a warm water anomaly initially formed in the subsurface (100-300 $\mathrm{m}$ depth) propagates eastward due to an oceanic Kelvin wave along the thermocline as represented by isotherms of $20-24{ }^{\circ} \mathrm{C}$ (Fig. 5a). The initial peak of the temperature anomaly is located on the eastern side of the WWE region. It is induced by the downwelling balanced mainly by the convergence of anomalous zonal surface currents and secondary by the meridional currents due to the Ekman transport (cf. Kessler and Kleeman 2000), according to a budget analysis on the continuity equation (not shown).

The SST rapidly warms in the Niño3.4 region when the subsurface signal reaches the surface by day 60 (Fig. 5b). Subsequently, this positive SSTA expands over the equatorial Pacific involving the eastward and equatorward surface wind anomalies. They are maintained for several months, especially in the northern off-equator. A part of the positive SSTA, accompanied by surface westerly anomalies, migrates westward and decays gradually in the western Pacific. This migration after June may be caused by the seasonal shrink of the warm pool.

Precipitation anomalies are shown in Fig. 5c. After day 60 , positive and negative precipitation anomalies appear at the southern and northern sides of the climatological ITCZ (black contour), indicating the southward shift of the ITCZ. This accompanies surface wind anomalies eastward and equatorward in the central equatorial Pacific (Fig. 5b), where the climatological wind is westward and northward, suppressing the latent heat flux (now shown). The weakened heat flux damping has the positive SSTA to expand westward and to persist after day 60 .

The time sequence of the WWE contribution in WWE3$160 \mathrm{E}$ is depicted in Fig. 6, in a similar manner to Fig. 5. Similar to WWE5-160E, a warm water anomaly is formed in the surface and subsurface layers, while a cold water anomaly appears in the far western Pacific until day 20. 


\section{Spatio-temporal structure (WWE5-160E)}

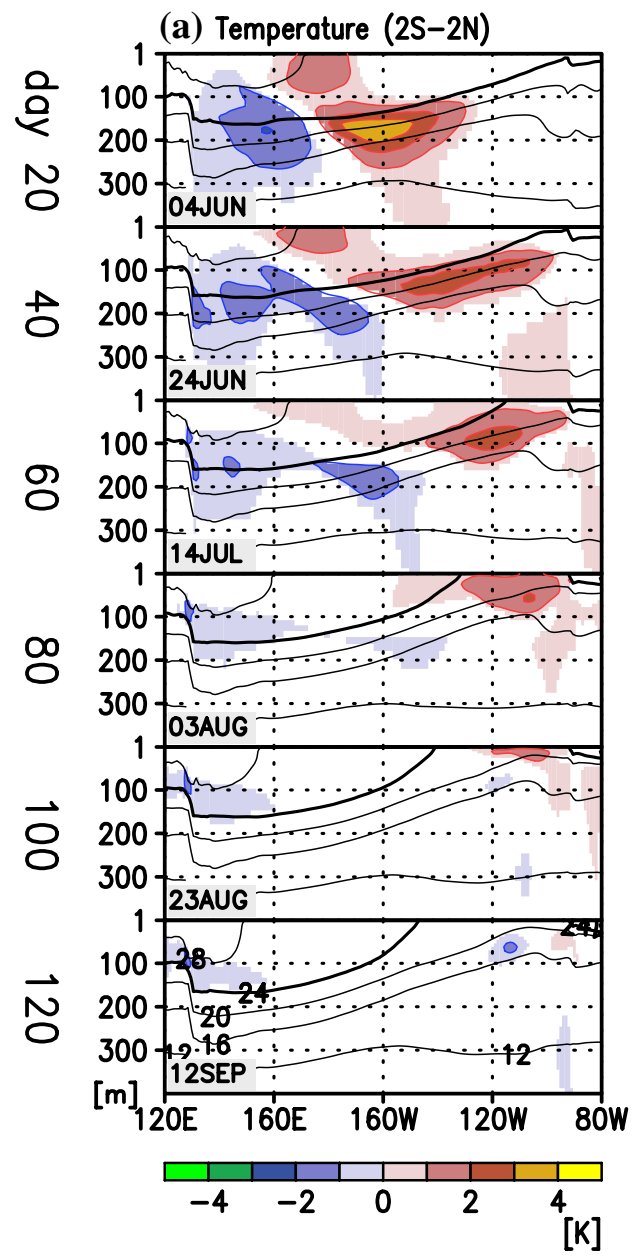

(b) SST \& Surface Wind

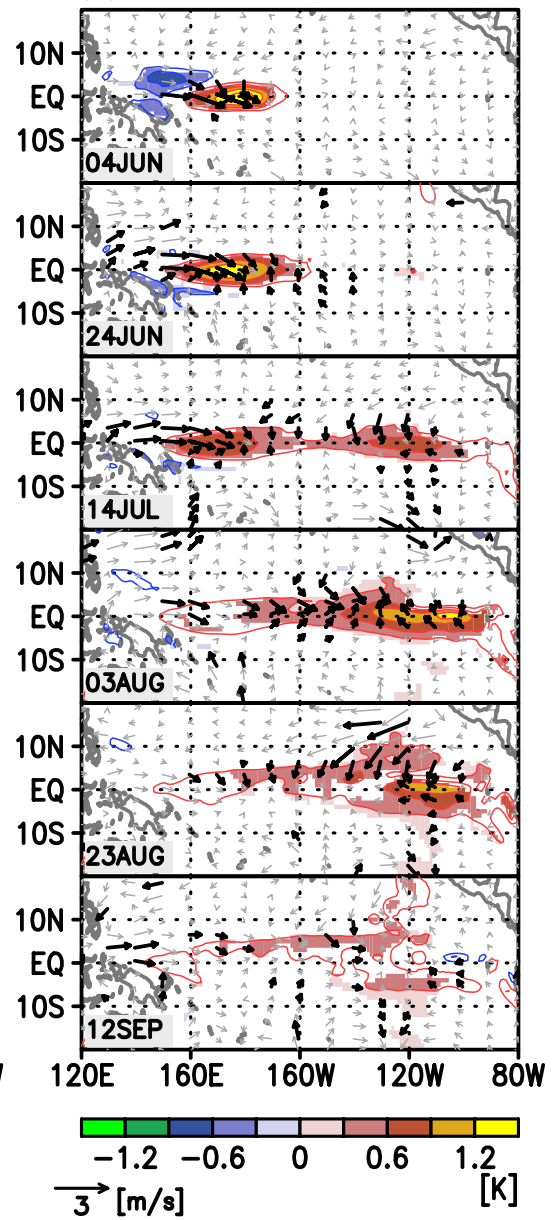

(c) Precipitation

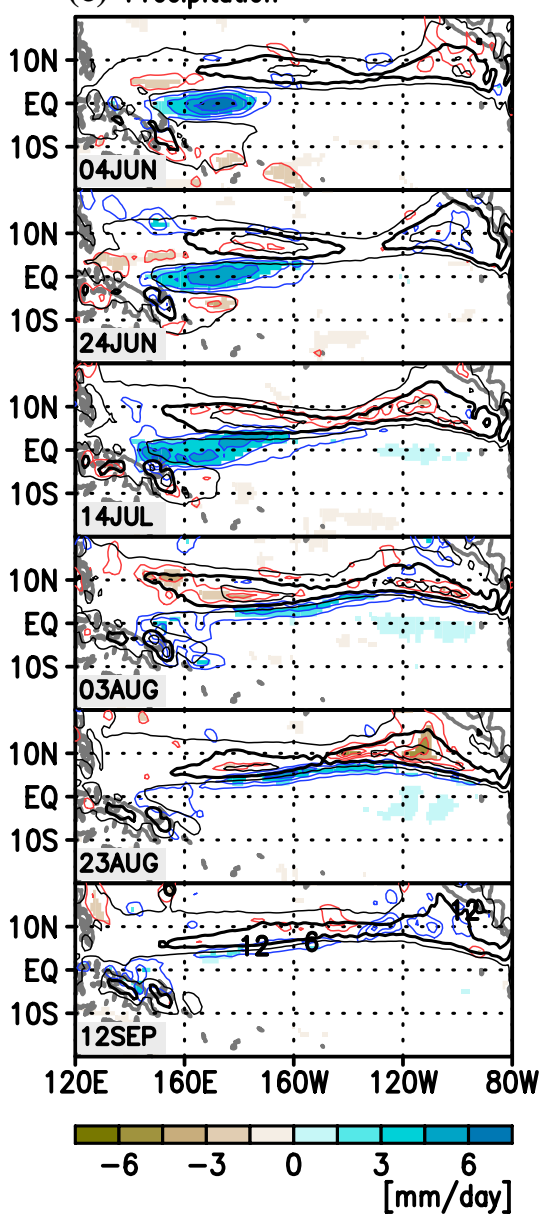

Fig. 5 Spatio-temporal structures of a $2^{\circ} \mathrm{S}-2^{\circ} \mathrm{N}$ averaged ocean temperature anomaly [shade, unit: $\mathrm{K}$ ] and its climatology [black contour, contour interval: $4{ }^{\circ} \mathrm{C}$ ] (a thick line corresponds to $24{ }^{\circ} \mathrm{C}$ ), b SSTA [shade, unit: $\mathrm{K}$ ] and $10 \mathrm{~m}$ horizontal wind anomaly [vector], and $\mathbf{c}$ precipitation anomaly [shade, unit: $\mathrm{mm} \mathrm{day}^{-1}$ ] and its climatology [contour, contour interval: $6 \mathrm{~mm} \mathrm{day}^{-1}$ ] (a thick line corresponds to $12 \mathrm{~mm} \mathrm{day}^{-1}$ ) for WWE5-160E. A 15-day running mean is applied for all values. Time proceeds from top to bottom by 20 days from day

While the positive SSTA accompanied by westerly anomalies shifts westward after day 60 in the western Pacific, the warm water signal in the subsurface propagates eastward along the thermocline. However, the subsurface signal that reaches the Niño1+2 region does not expand after day 80 (Fig. 6b). Significant anomalies of precipitation and surface winds are restricted over the western Pacific. That is, the SST response is limited in the far eastern Pacific with a very weak atmospheric response. These are a discernible difference from the atmosphere-ocean response in WWE5-160E.

WWE5-160W and WWE5-180 show responses quite similar to WWE5-160E, and the WWE7 experiments result in WWE contributions similar to WWE5-160E except for
20. Actual date of each figure is shown at the bottom left-hand side of each panel. Shades are depicted only for regions exceeding $90 \%$ statistical confidence by Welch's t-test, and red (blue) contours with the same interval of shades indicate positive (negative) values except for c, where red (blue) contours indicate negative (positive) values. Black vectors in $\mathbf{b}$ indicate the zonal or meridional component exceeds $90 \%$ statistical confidence. See the vector scale at the bottom left-hand side of $\mathbf{b}$ for the wind magnitude

the shorter duration of significant signals. Likewise, the three WWE3 experiments share a similarity in the coupled response. In the WWE1 experiments, the surface warming occurs with shorter period and weak responses of wind and precipitation in the eastern Pacific.

\subsection{ITCZ southward shift and equatorward surface currents}

The southward shift of the ITCZ involved with anomalous winds was identified in WWE5-160E (Fig. 5c). Its temporal relationship with equatorward surface wind, causing the anomalous equatorward surface currents, is shown in Fig. 7a. After June, the equatorial precipitation anomaly 


\section{Spatio-temporal structure (WWE3-160E)}

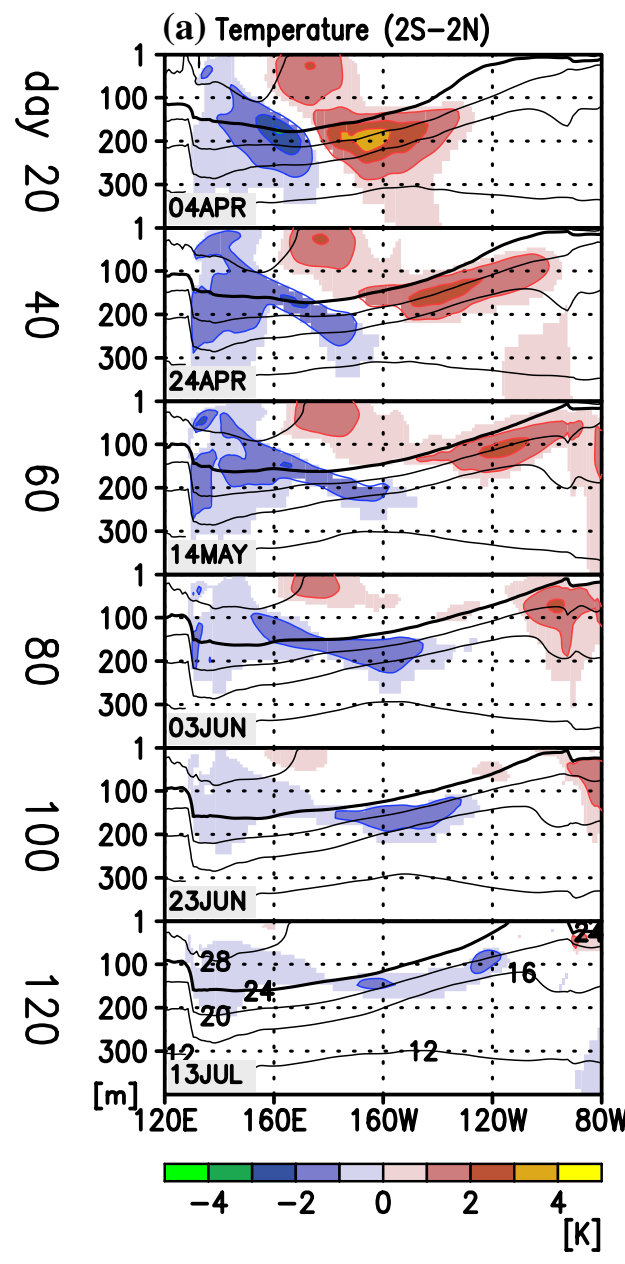

(b) SST \& Surface Wind

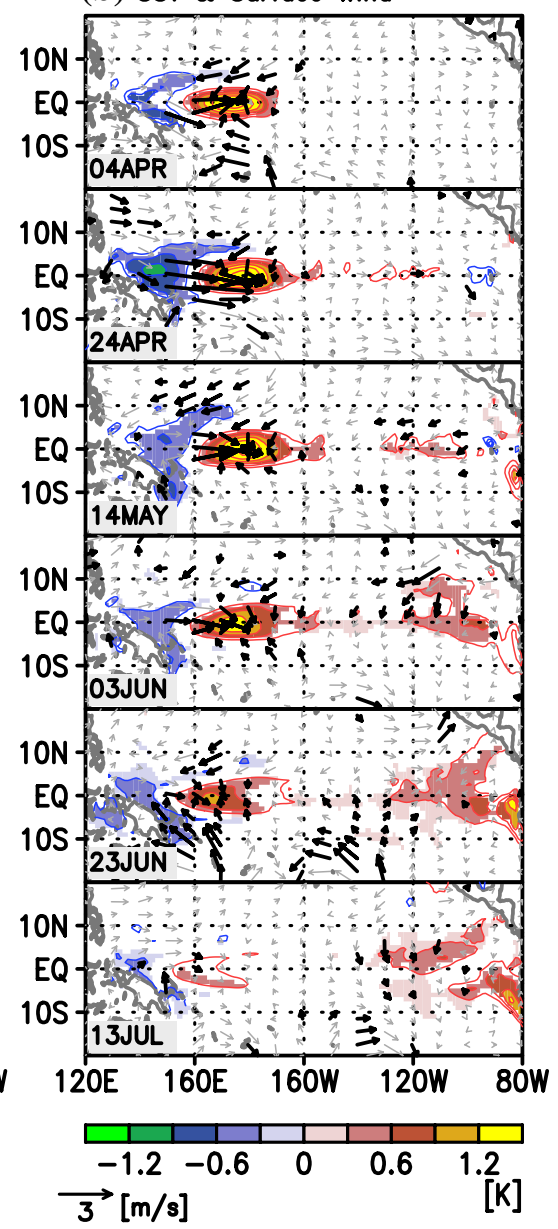

(c) Precipitation

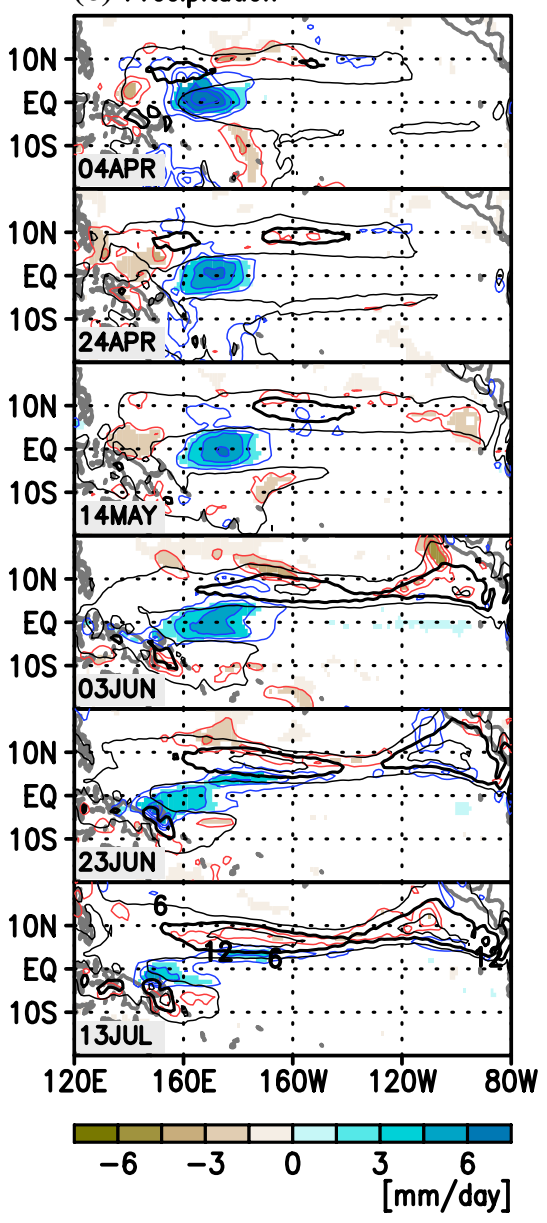

Fig. 6 As for Fig. 5, except for WWE3-160E

(orange line) is accompanied by the equatorward wind convergence (blue line). From July to mid-August, the precipitation is activated to the south of the background ITCZ (red line) and the equatorward surface wind anomaly is correspondingly intensified more at the northern off-equator (blue line), driving the anomalous equatorward surface current beneath the winds persisting until November (black line). The meridional advection due to the anomalous current may warm the eastern Pacific in the northern off-equator. Such a persisting equatorward current is not observed at the southern off-equator (figure not shown).

In contrast, for WWE3-160E, there is no robust peak in the signals of the precipitation and meridional wind, although the precipitation anomaly to the south of the ITCZ is weakly positive during the boreal summer. As shown in Fig. 4a, the Niño3.4 warming after August is not statistically significant having the scattered ensemble members, implying that the interaction of SSTAs with the ITCZ after July might occur only in a few members.

\section{Mechanism}

\subsection{Processes responsible for WWE-induced warming}

As shown in the previous section, a widespread warming over the equatorial Pacific is induced by an imposed WWE, especially in WWE5-160E. To clarify the mechanism of the warming, we conducted a heat budget analysis for the mixed layer (ML). According to Graham et al. (2014), the spatially and temporary varying mixed layer depth $(D)$ is defined as the depth at which a density difference of 0.125 $\mathrm{kg} \mathrm{m}^{-3}$ compared to the surface is first reached. The temperature $(T)$ tendency averaged in the ML is approximately described as the sum of the zonal and meridional advections, vertical advection including the entrainment of cool water into the ML, and surface heat fluxes:

$\frac{\partial T}{\partial t}=-u \frac{\partial T}{\partial x}-v \frac{\partial T}{\partial y}-\frac{w_{e} \Delta T}{D}+\frac{Q_{l h}+Q_{s h}}{\rho C_{p} D}+R$, 


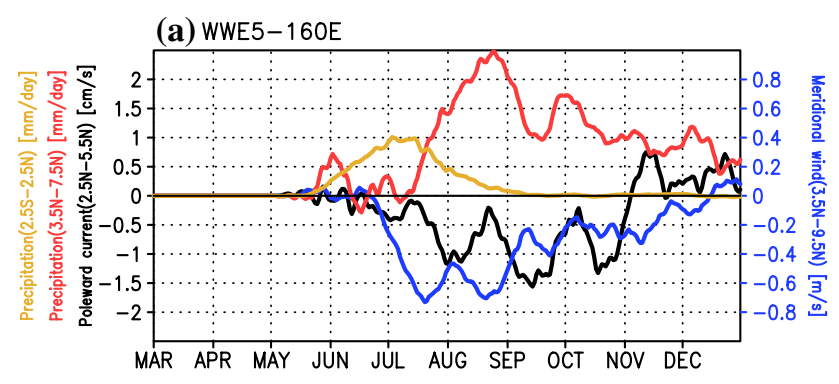

(b) WWE3-160E

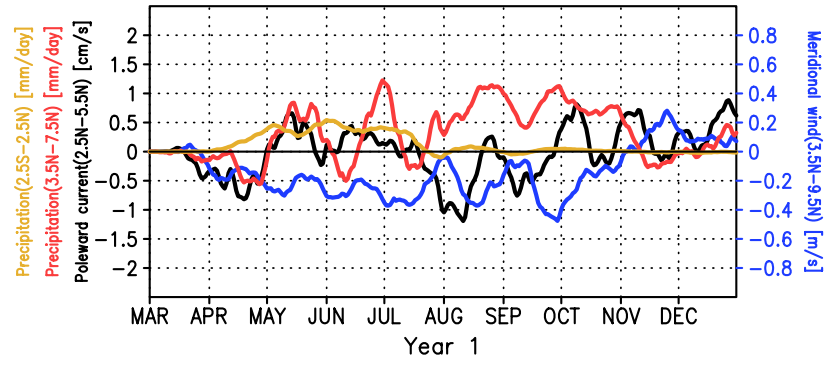

Fig. 7 Time series of $120^{\circ}-170^{\circ} \mathrm{W}$ averaged anomalies of the meridional currents averaged over $2.5^{\circ}-5.5^{\circ} \mathrm{N}$ (black solid) in the mixed layer (defined in Sect. 4.1), the meridional surface winds averaged over $3.5^{\circ}-9.5^{\circ} \mathrm{N}$ (blue), and the precipitation averaged over $2.5^{\circ}$ $\mathrm{S}-2.5^{\circ} \mathrm{N}$ (orange) and $3.5^{\circ}-7.5^{\circ} \mathrm{N}$ (red) for a WWE5-160E and $\mathbf{b}$ WWE3-160E, smoothed by a 15 -day running mean

where $u$ and $v$ indicate the vertically-averaged zonal and meridional ocean currents in the ML, respectively, $\rho$ is seawater density in the ML, $C_{p}$ is specific heat $(3940 \mathrm{~J}$ $\mathrm{kg}^{-1}{ }^{\circ} \mathrm{C}^{-1}$ ), and $\Delta T$ indicates the temperature difference between the ML and its base. $Q_{l h}$ and $Q_{s h}$ are latent and sensible heat fluxes, respectively. $R$ represents the residual term, including surface radiation. The vertical entrainment velocity $\left(w_{e}\right)$ is given by

$w_{e}=\frac{\partial D}{\partial t}+u_{D} \frac{\partial D}{\partial x}+v_{D} \frac{\partial D}{\partial y}+w_{D}$

where $u_{D}, v_{D}$, and $w_{D}$ indicate the zonal, meridional, and vertical velocity at the ML base, respectively. By decomposing variables into means and deviations in Eq. (3), the tendency equation of the ML temperature anomaly is derived as
The overbars and primes indicate the basic state values including seasonal variation and anomalies, respectively, smoothed by a 15-day running mean. The bulk effect of the entrainment is assumed by defining that $H\left(\overline{w_{e}}\right)=1$ for $\overline{w_{e}}>0$ and $H\left(\overline{w_{e}}\right)=0$ for $\overline{w_{e}} \leq 0$. LN1 is the sum of linear advection terms due to current anomalies, LN2 is the sum of linear advection terms due to basic state current, NL is a combined nonlinear advection term, and Q represents the heat flux anomalies.

Figure 8 shows the tendency of $T^{\prime}$ over the Niño3.4 region along the equator for WWE5-160E (gray curve). Two clear peaks are discernible in June and July. These peaks are well reproduced by Eq. (5), and are mainly related to the zonal component of LN1 (black curve in the second panel) and the vertical and meridional components of LN2 (cyan and magenta curves in the third panel). In the northern off-equator (Fig. 9), the meridional component of LN1 (magenta curve in the second panel) and the latent heat flux (black curve in the fifth panel) also persistently contributes to warming after July.

The WWE in WWE5-160E induces Niño3.4 warming in the ML by the following processes. First, the linear zonal advection of LN1 warms the region in June, which is responsible for the first peak of the warming tendency, associated with the eastward surface current anomaly of the WWE-forced oceanic Kelvin wave as suggested by Harrison and Schopf (1984). The zonal nonlinear advection in NL also contributes to the warming since the eastward surface current anomaly is negatively correlated with the zonal gradient of the anomalous SST at the east of the WWE. Second, the vertical and meridional advection terms in LN2 induce the second peak of warming in July as the thermocline tilt becomes steeper involved with the equatorial upwelling (Fig. 3b). Then, the background current in the ML expands the warm water anomaly poleward. In addition, meridional advection in LN1 results in a warming tendency in the Niño3.4 region persistently from July to October mainly in the northern off-equator (Fig. 9). As the background SST increases poleward near the cold tongue, this warming tendency is induced by the equatorward anomalous surface current (Fig. 7a), resulting from the wind anomaly in association with the

$$
\begin{aligned}
& \frac{\partial T^{\prime}}{\partial t}=\underbrace{-u^{\prime} \frac{\partial \bar{T}}{\partial x}-v^{\prime} \frac{\partial \bar{T}}{\partial y}-\frac{H\left(\overline{w_{e}}\right) w_{e}^{\prime} \overline{\Delta T}}{D}}_{\mathrm{LN} 1} \underbrace{-\bar{u} \frac{\partial T^{\prime}}{\partial x}-\bar{v} \frac{\partial T^{\prime}}{\partial y}-\frac{H\left(\overline{w_{e}}\right) \bar{w}_{e}(\Delta T)^{\prime}}{D}}_{\mathrm{LN} 2} \\
& \underbrace{-u^{\prime} \frac{\partial T^{\prime}}{\partial x}-v^{\prime} \frac{\partial T^{\prime}}{\partial y}-\frac{H\left(\overline{w_{e}}\right) w_{e}^{\prime}(\Delta T)^{\prime}}{D}}_{\mathrm{NL}}+\underbrace{+\frac{Q_{l h}^{\prime}+Q_{s h}^{\prime}}{\rho C_{p} D}}_{\mathrm{Q}}+R^{\prime} .
\end{aligned}
$$




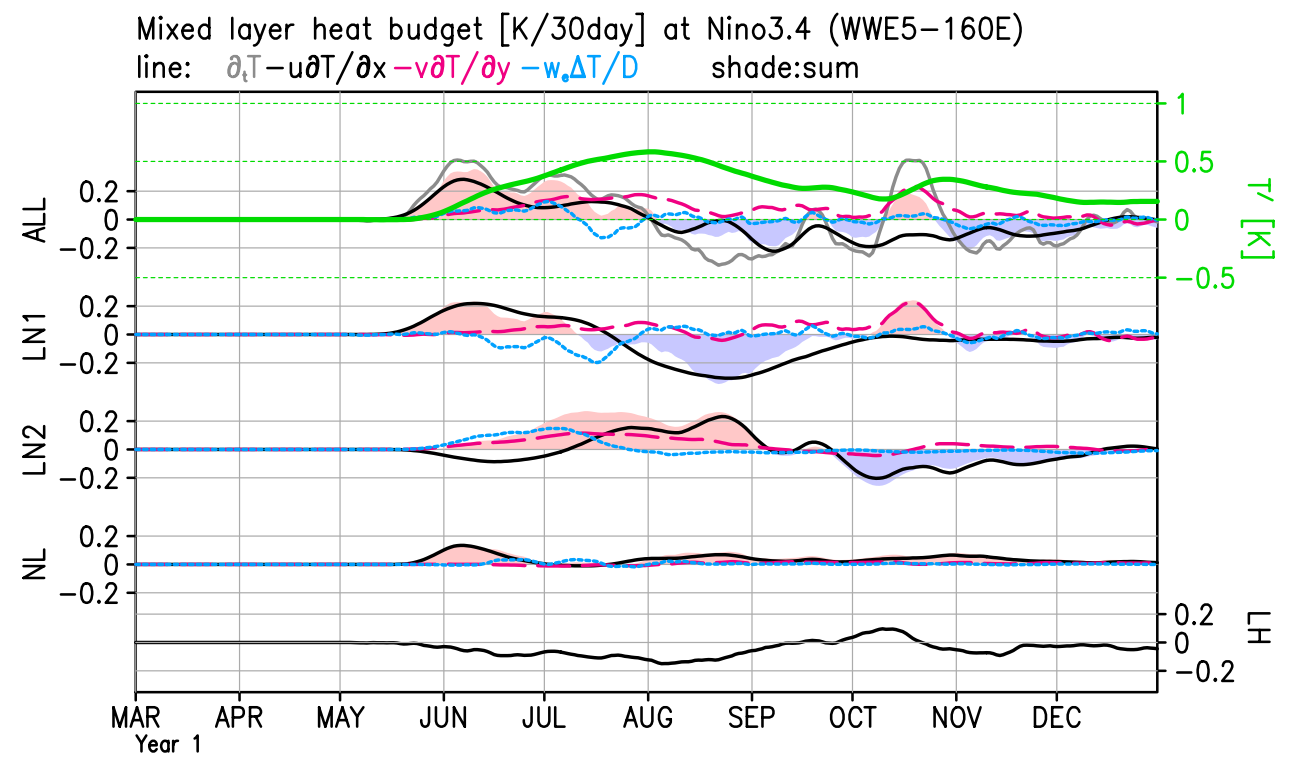

Fig. 8 Time series of the temperature anomaly [green-solid line, unit: K] averaged over $120^{\circ}-170^{\circ} \mathrm{W}$ and $1.5^{\circ} \mathrm{S}-1.5^{\circ} \mathrm{N}$ in the mixed layer, and its tendency [gray-solid line in ALL] and the results of the heat budget analysis [unit: $\mathrm{K}\left(30\right.$ days $^{-1}$ ] for WWE5-160E. In ALL, the shade indicates the sum of the advective terms (LN1, LN2, NL) and Q in Eq. (5), and black-solid, magenta-dashed, and cyan-dotted lines indicate the zonal, meridional, and vertical components of the advective terms, respectively. Shades in LN1, LN2, and NL indicate the sums of the zonal (black-solid line), meridional (magenta-dashed line), and vertical (cyan-dotted line) components of LN1, LN2, and $\mathrm{NL}$ in Eq. (5), respectively. Black line in LH indicates the latent heat flux anomaly
Fig. 9 As for Fig. 8, except for $2.5^{\circ} \mathrm{N}-5.5^{\circ} \mathrm{N}$
Mixed layer heat budget [K/30day] at Nino3.4 (WWE5-160E)

line: $\partial_{\mathrm{t}} \mathrm{T}-\mathrm{u} \partial \mathrm{T} / \partial \mathrm{x}-\mathrm{v} \partial \mathrm{T} / \partial \mathrm{y}-\mathrm{w}_{\mathrm{e}} \Delta \mathrm{T} / \mathrm{D}$ shade:sum

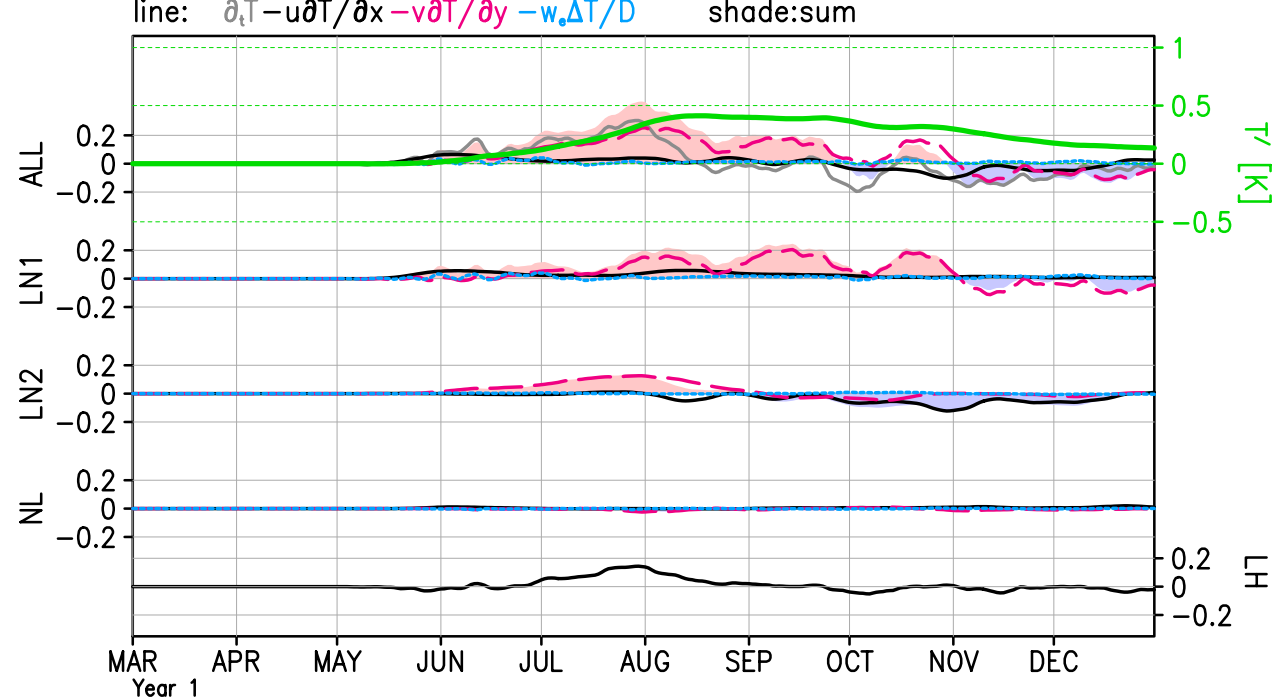

southward shift of the ITCZ. Correspondingly, the speed of trade winds is weakened (Fig. 5b), reducing evaporation (Fig. 9). This causes the warm water anomaly to spread toward the central Pacific in the northern off-equator (Fig. 9), which is called the wind-evaporation-SST (WES) feedback (Xie and Philander 1994; Xie 1996).

The process for WWE3-160E is confirmed based on Fig. 10, in a similar manner to Fig. 8. The Niño3.4 warming initially occurs only due to the zonal components of LN1 and NL in April. After July, a warming tendency by the meridional component of LN1 is observed in the northern off-equator (not shown), although the Niño3.4 SSTA is scattered among the ensemble members of WWE3-160E (Fig. 4a). This implies that a part of the ensemble members, having southward shift of the ITCZ, might show the warming in boreal summer associated with the anomalous equatorward surface current (Fig. 7b). 
Fig. 10 As for Fig. 8, except for WWE3-160E

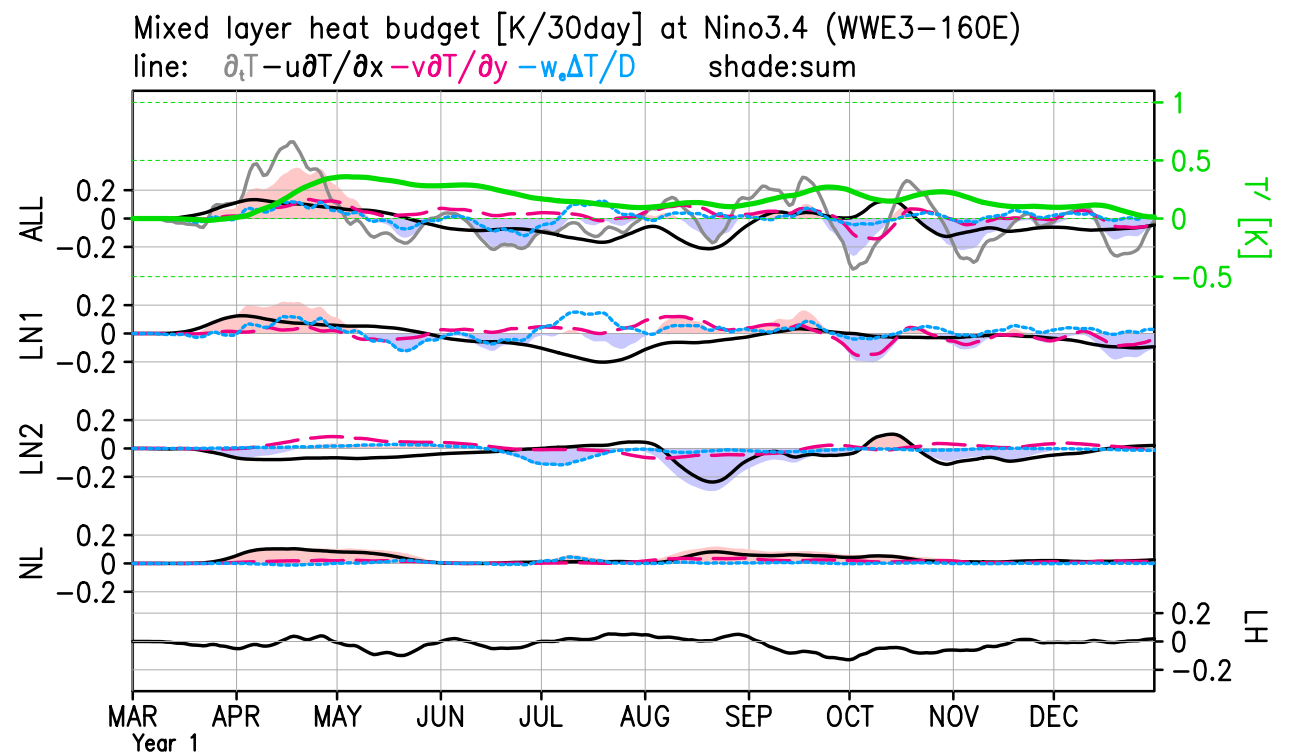

\subsection{Role of background seasonality}

With respect to the Niño3.4 warming, it is found that the seasonality of the ocean and atmosphere plays a crucial role as schematically shown in Fig. 11. The signal of the subsurface warm water propagates eastward between isotherms of 20 and $24{ }^{\circ} \mathrm{C}$ (Figs. 5a, 6a). Therefore, the steepness of the thermocline tilt and corresponding zonal gradient of the temperature in the eastern Pacific are crucial to determine where the surface warming occurs (cf. Harrison and Schopf 1984). The slope of the thermocline is the flattest in May (cf. Fig. 5a) after which the WWEinduced warm signal reaches the easternmost equatorial Pacific (Fig. 11b). The slope becomes steeper after July (cf. Fig. 3), corresponding to the strengthening of the equatorial upwelling in the eastern Pacific, resulting in the surface warming near the Niño3.4 region through the vertical advection of the subsurface warm water (Fig. 11c).

The ITCZ located near $10^{\circ} \mathrm{N}$ is active over the eastern equatorial Pacific from June to October (Fig. 2c, d). Thus, the positive SSTA in the eastern Pacific can easily interact with deep convection, causing a southward shift of the ITCZ in WWE5-160E (Fig. 11c). This is accompanied by the equatorward surface wind over the northern off-equator, which reduces the poleward surface current and results in the anomalous warming in the northern side of the cold tongue. In addition, the weakening of the trade wind over the southern side of the background ITCZ also contributes to the warming due to the reduction in evaporation.
Fig. 11 Schematic figure of the relationship between the timing of a WWE forcing and background conditions of precipitation and thermocline. Red shadings indicate the anomalous warm water and black arrows indicate surface wind anomalies. Gray objects represent the background ITCZ and black lines indicate isotherms of background ocean temperature. a WWE forcing and warm water anomalies in the surface and subsurface layers. b 2 months after a WWE in March. $\mathbf{c} 2$ months after a WWE in May (b) 2 month after WWE in March

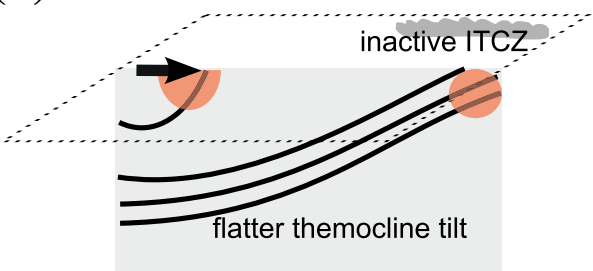

(c) 2 month after WWE in May

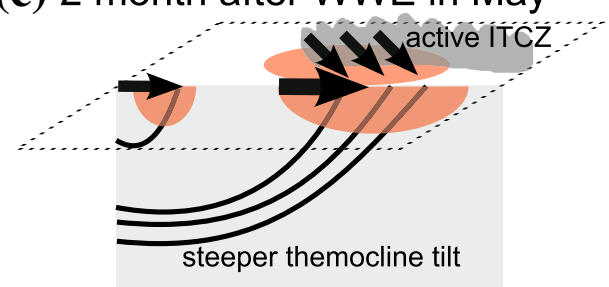




\subsection{Generality}

The generality of the mechanism explained above is confirmed by using 12 sets of ensembles. Figure 12 collectively plots the central timings and longitudes of the imposed WWEs (crosses), the maxima of the warm water anomaly in the subsurface (open circles), and the SSTA maxima on the eastern/western side of $150^{\circ} \mathrm{W}$ (closed circles/triangles) over the background seasonal march of precipitation averaged over $5^{\circ}-15^{\circ} \mathrm{N}$ (shading), temperature in the surface layer (0-50 m depth) (hatched area), and the warm pool edge defined as $28^{\circ} \mathrm{C}$ SST isotherm (dashed line).

Climatological precipitation associated with the ITCZ (shading) is seasonally active during the boreal summer from June to October over the eastern Pacific. In addition, the area of climatological surface-layer temperature of $20-24{ }^{\circ} \mathrm{C}$ (hatched area), where the initial surface warming may appear as indicated in Sect. 4.2, expands after June and reaches near $120^{\circ} \mathrm{W}$, corresponding to the seasonal strengthening of the equatorial cold tongue or equatorial upwelling in the eastern Pacific. In the western Pacific, the edge of the warm pool expands the most in May.

Subsurface temperature anomalies (open circles) begin with the imposed WWE forcing in each set of experiments (crosses). The warm water anomaly appears in the eastern side of the WWE and its signal propagates eastward due to an oceanic Kelvin wave. In the WWE3 experiments, the subsurface warm water outcrops and continues weakly in the easternmost Pacific (near $90^{\circ} \mathrm{W}$ ), while surface warming continues in the eastern Pacific for several months in the WWE5 experiments (closed circle). Considering all the ensemble sets, greater and more persistent surface warming in the eastern Pacific occurs where climatological precipitation is active after outcropping of the subsurface warm water near the Niño3.4 region, indicating the importance of both the seasonally steeper slope of the climatological thermocline and the interaction of SSTAs with the active ITCZ. An exception is WWE1-160W, where the amplitude of the SSTA maximum is larger at $110^{\circ} \mathrm{W}$ for 2 months, due mainly to NL of Eq. (5) only for 1 month (not shown).

In the western Pacific, surface warming (triangles) concentrates near the eastern edge of the warm pool (dashed line), the reason of which can be interpreted as follows. Precipitation is activated near the edge due to the SSTA induced by WWE over the western Pacific. Then, the largescale motion forced with the precipitation anomaly pushes the edge eastward, although it is shifted to the west because of the seasonal migration of the warm pool in the model.
Fig. 12 Paths of the warm water anomaly on the subsurface (open circles) and maximum points of the SSTA on the eastern side of $150^{\circ} \mathrm{W}$ (closed circles) and on the western side of $150^{\circ} \mathrm{W}$ (open triangles) for each experiment. The color corresponds to each experiment and the size corresponds to the amplitude of anomalies; see right-hand side. Shade indicates the background precipitation near the ITCZ $\left(5^{\circ}-15^{\circ} \mathrm{N}\right)$ [unit: $\mathrm{mm}$ day $^{-1}$. The hatching indicates the area between 20 and $24{ }^{\circ} \mathrm{C}$ of the background ocean temperature averaged between $2^{\circ} \mathrm{S}$ and $2^{\circ} \mathrm{N}$ in the surface layer (from the surface to a depth of $50 \mathrm{~m}$ ). The dashed line indicates the eastern edge of the warm pool, or $28^{\circ} \mathrm{C}$ contour of the background SST

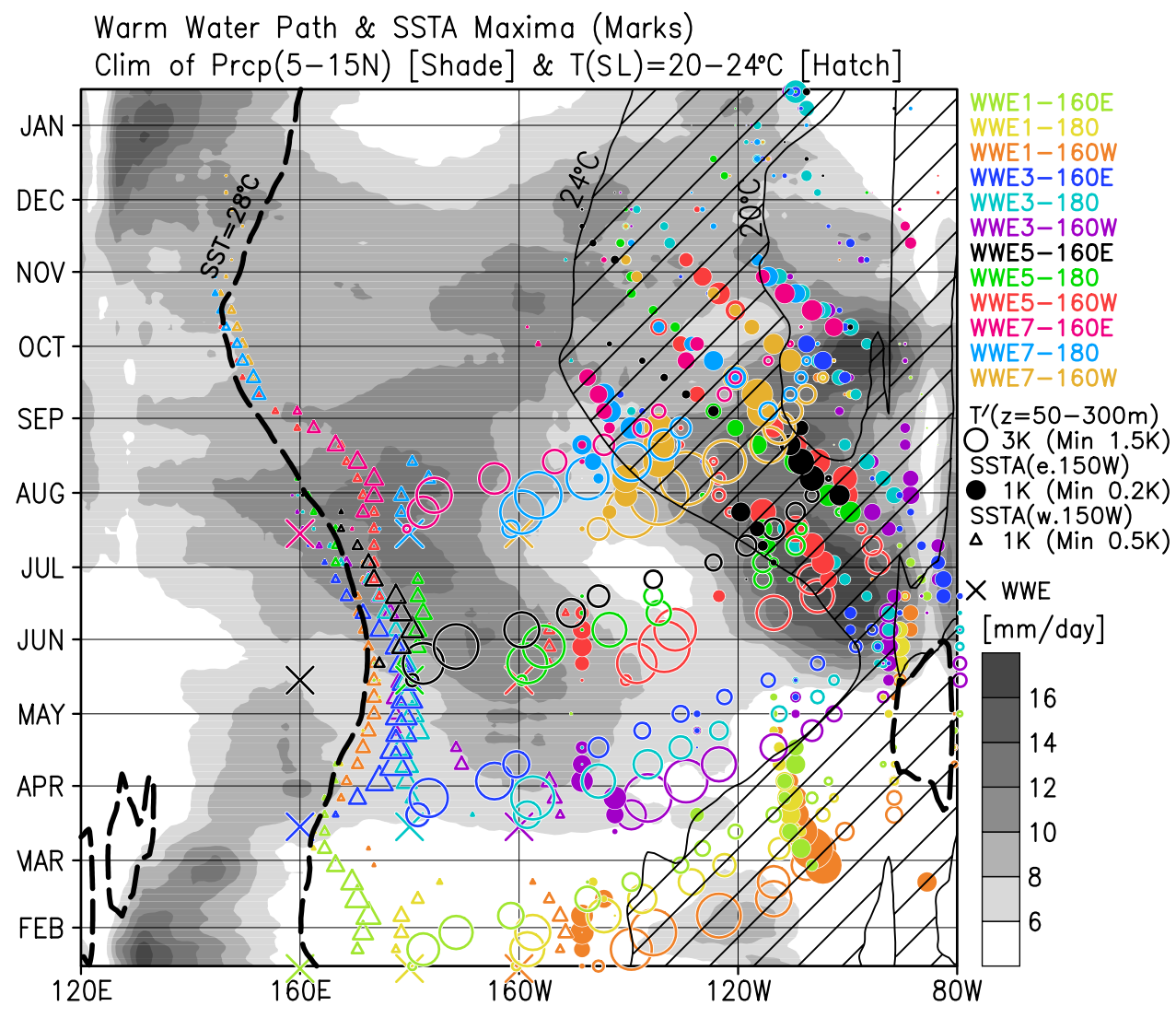




\section{WWE impact on the ENSO cycle}

The impact of WWEs on the ENSO cycle is investigated in this section. We conducted an extra set of numerical experiments, referred to as HIST-WWE5-160E, which is the same as WWE5-160E except for the ocean and atmosphere initial values given from the historical run on January 1 during the period 1981 to 2005 (Sect. 2). A set of experiments without WWE forcing is referred to as HIST-REF. Because of the initial subsurface anomalies, the ocean condition develops into either a warm or a cold phase of the ENSO cycle, or stays neutral without prescribed WWEs. By prescribing a WWE similar to WWE5-160E, we can estimate the effect of a WWE in May on the subsequent development of ENSO. The number of ensemble members is 25 , and by the method described below, we classify the set into four cases: W (moderately warm), E (extremely warm), N (neutral), and $C$ (cold) following the Niño3.4 SSTA in HIST-REF. As the WWE is prescribed in May, the Kelvin wave induced by the WWE reaches the eastern Pacific during July and August; therefore, case W/E (C) is defined as an experiment in which Niño3.4 SSTA from July to November is higher (lower) than $0.5 / 3.0 \mathrm{~K}(-0.5 \mathrm{~K})$; otherwise, it is classified as case $\mathrm{N}$. The 25 years are classified into 6,2 , 7 , and 10 for $\mathrm{W}, \mathrm{E}, \mathrm{N}$, and $\mathrm{C}$. The results described below are not sensitive to the sampling method.

The Niño3.4 indices in each case are depicted in Fig. 13. Comparing HIST-WWE5-160E with HIST-REF, the WWE affects cases $\mathrm{W}$ and $\mathrm{N}$, with a contribution of $0.5 \mathrm{~K}$ to 1 $\mathrm{K}$ warming for several months. On the other hand, cases $\mathrm{E}$ and $\mathrm{C}$ are insensitive to the prescribed WWE. The horizontal structures of the WWE contribution to SST are shown in Fig. 14a-d. In case N, the SST warms a wide area of the tropical Pacific, and the ITCZ shifts southward as in WWE5-160E (Fig. 14a, e). Similarly, in case W, surface warming expands over the tropical Pacific centered in the Niño3.4 region, involving a southward shift of the ITCZ (Fig. 14b, f). Interestingly, two of case W were modulated by the WWE into extreme warm events, accompanied by subsequent westerly anomalies over the western Pacific, as shown by Fedorov et al. (2015). However, the SST response to a WWE is weak in case E (Fig. 14c, g) since Niño3.4 SST almost reaches the "maximum potential intensity" of El Niño events that corresponds to the temperature determined by the radiative-convective equilibrium (Jin et al. 2003). Larger sample number is required to conclude the inefficiency of WWEs for case E. On the other hand, there are very weak signals in the precipitation field in case $\mathrm{C}$ (Fig. 14d, h), even though the slope of the thermocline is steeper in the eastern Pacific during cold phases. This may be caused by the northward shift of the ITCZ associated with a cold SSTA over the equatorial Pacific, resulting in (a) HIST-REF(Dashed) HIST-WWE5-160E(Solid)

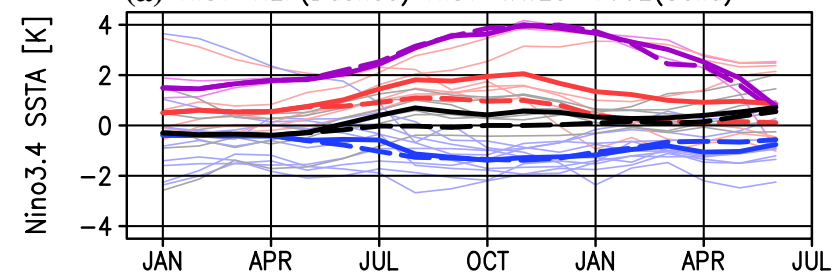

(b) Diff. of HIST-WWE5-160E and HIST-REF

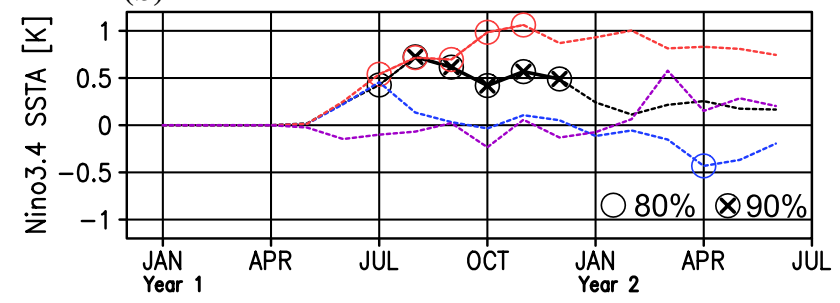

Fig. 13 a Niño3.4 SSTA in HIST-REF (dashed lines) and HISTWWE5-160E (solid lines) for cases N (black), W (red), E (purple), and $\mathrm{C}$ (blue). The thin curves indicate individual members in HISTWWE5-160E and the thick curves are ensemble mean anomalies. b Differences in Niño3.4 SSTA between HIST-REF and HIST-WWE5$160 \mathrm{E}$ for each case, calculated using the ensemble means. Crossed and open circles indicate the differences significant at the 90 and $80 \%$ levels by Welch's t-test, respectively

weak interaction between the WWE-induced warm water and the ITCZ.

The ensemble members of HIST-WWE5-160E were also classified into recharged, discharged, and neutral cases based on anomalies of upper ocean heat content averaged over the equatorial Pacific in May (HC) (figure not shown, cf. Meinen and McPhaden 2000). Although the WWE contribution is not statistically significant in any cases, the WWE in May is more efficient to increase the Niño3.4 SST for the positive HC (recharged) than the negative HC (discharged), consistent with Lengaigne et al. (2004).

While the SSTA induced by a WWE in May can interact with the ITCZ in cases $\mathrm{W}$ and $\mathrm{N}$, there is no interaction with the ITCZ in case C. This indicates that the effect of the WWEs is asymmetric to the ENSO phase associated with the difference in atmospheric conditions, not only that in oceanic heat content (Perigaud and Cassou 2000; Lian et al. 2014; Hu et al. 2014; Fedorov et al. 2015).

\section{Discussion}

From the series of WWE experiments conducted, it is clear that background seasonality in both the atmosphere and ocean is of importance in a response to the imposed WWE forcing (e.g., Fig. 11). However, the sensitivity of the response to the mean seasonal march is not guaranteed in nature because of potential model biases in the climatological ITCZ and thermocline. Figure 15 shows 

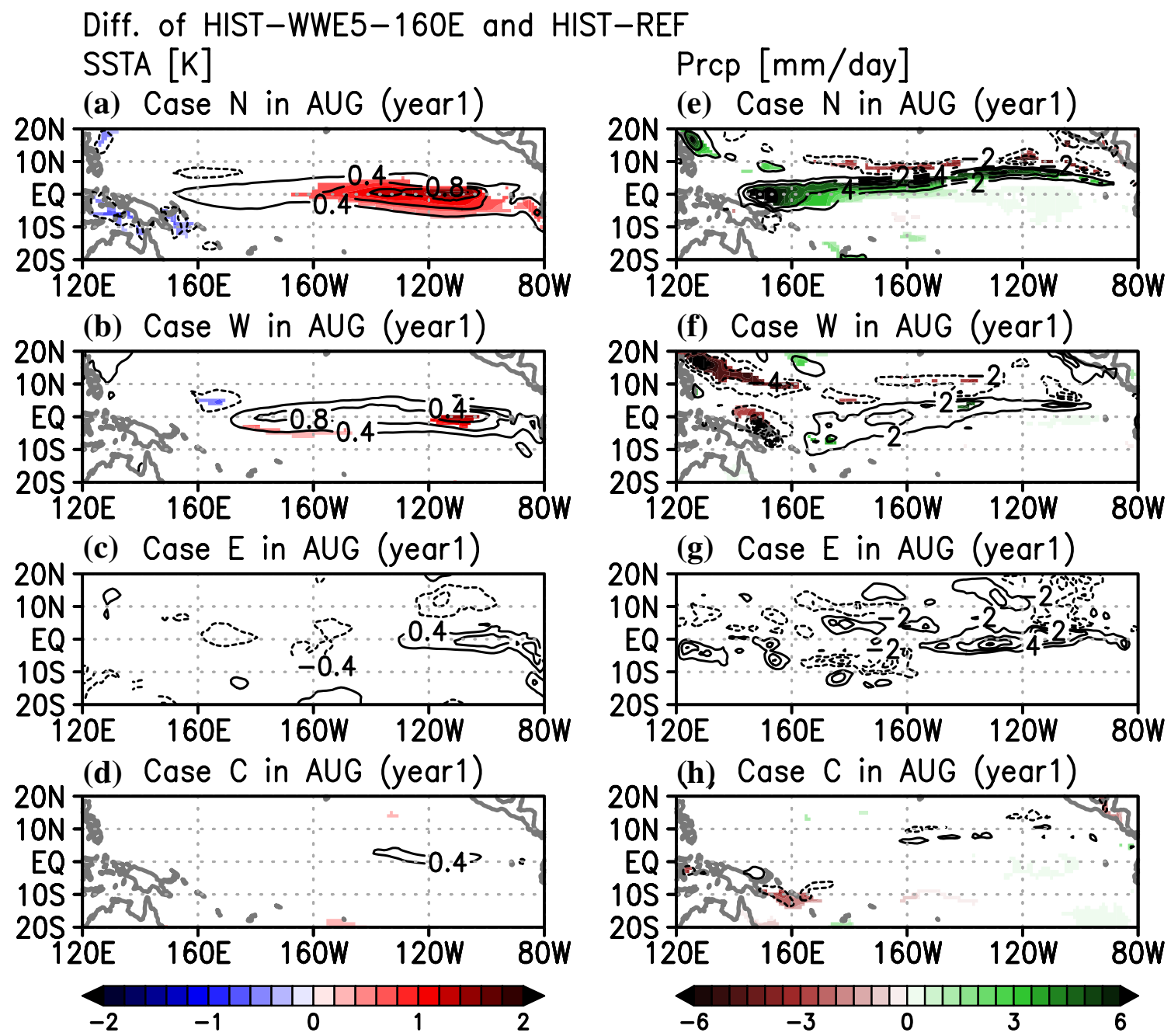

Fig. 14 Differences in a-d SSTA $[K]$ and $\mathbf{e}-\mathbf{h}$ precipitation $\left[\mathrm{mm} \mathrm{day}^{-1}\right.$ ] between HIST-REF and HIST-WWE5-160E for each case in August of year 1. The $80 \%$ significant value by Welch's t-test is

the mean seasonal variations of the observed precipitation averaged over $5^{\circ}-15^{\circ} \mathrm{N}$ (gray shading) and ocean temperature averaged over $2^{\circ} \mathrm{S}-2^{\circ} \mathrm{N}$ in the surface layer (hatched area). A comparison with Fig. 12 indicates that, at the eastern Pacific, the model is indeed biased to have too strong an ITCZ and a larger seasonal variation of the $20-24{ }^{\circ} \mathrm{C}$ isoline, but they are unlikely to be significant for the mechanism described in Sect. 4. Specifically, precipitation over $5^{\circ}-15^{\circ} \mathrm{N}$ is active at the eastern Pacific and the area with an surface-layer temperature of $20-24{ }^{\circ} \mathrm{C}$ reaches $120{ }^{\circ} \mathrm{W}$ from June to September, both of which are consistent between the model and the observations. The possible paths of oceanic Kelvin waves (phase speed is assumed as $2.2 \mathrm{~m} \mathrm{~s}^{-1}$, e.g., McPhaden 2002) indicate that the WWEs inside the thick dotted lines in the figure may efficiently warm the eastern Pacific associated with the interaction with the ITCZ. The probability shaded. The contour intervals of the SSTA and precipitation anomaly are $0.4 \mathrm{~K}$ and $2 \mathrm{~mm} \mathrm{day}^{-1}$, respectively

density function (PDF) of the observed WWE occurrences (red shading, see Fig. 16a in Appendix) is higher between $140^{\circ} \mathrm{E}$ and $160^{\circ} \mathrm{W}$. Therefore, the rhomboidal area between the thick-dotted lines and red areas in Fig. 15 defines the preferable set of combination for timings and longitudes of the WWEs that maximize Niño3.4 warming. WWEs in May are indeed thought favorable to warming the Niño3.4 region, or triggering El Niño in the subsequent winter.

A spurious peak of the model's climatological precipitation near the dateline may exaggerate the western Pacific atmospheric response to SST anomalies (Figs. 5, 6, and 12). However, the Niño3.4 warming associated with the ITCZ southward shift is caused by local processes in the eastern Pacific, as shown in Sect. 4.1. Thus, this bias would not be crucial for the present results, although their representativeness for nature needs to be further clarified by 
Fig. 15 Gray color indicates the background precipitation of GPCP data averaged between $5^{\circ} \mathrm{N}$ and $15^{\circ} \mathrm{N}$ [unit: $\mathrm{mm} \mathrm{day}^{-1}$ ]. The solid line and hatching indicate the $22{ }^{\circ} \mathrm{C}$ contour and the area between 20 and $24{ }^{\circ} \mathrm{C}$ of the background ocean temperature of Ishii and Kimoto (2009) averaged between $2^{\circ} \mathrm{S}$ and $2^{\circ}$ $\mathrm{N}$ in the surface layer (from the surface to a depth of $50 \mathrm{~m}$ ). Dotted lines indicate eastward propagating paths with a phase speed of $2.2 \mathrm{~m} \mathrm{~s}^{-1}$ assuming those of typical oceanic Kelvin waves in the equatorial Pacific. Red color indicate the probability density function (PDF) of WWE occurrences [longitude ${ }^{-1}$ ] shown in Fig. 16 (top) in Appendix. Note the value of the PDF is constant in time, although it is partly overlapped by gray in this figure

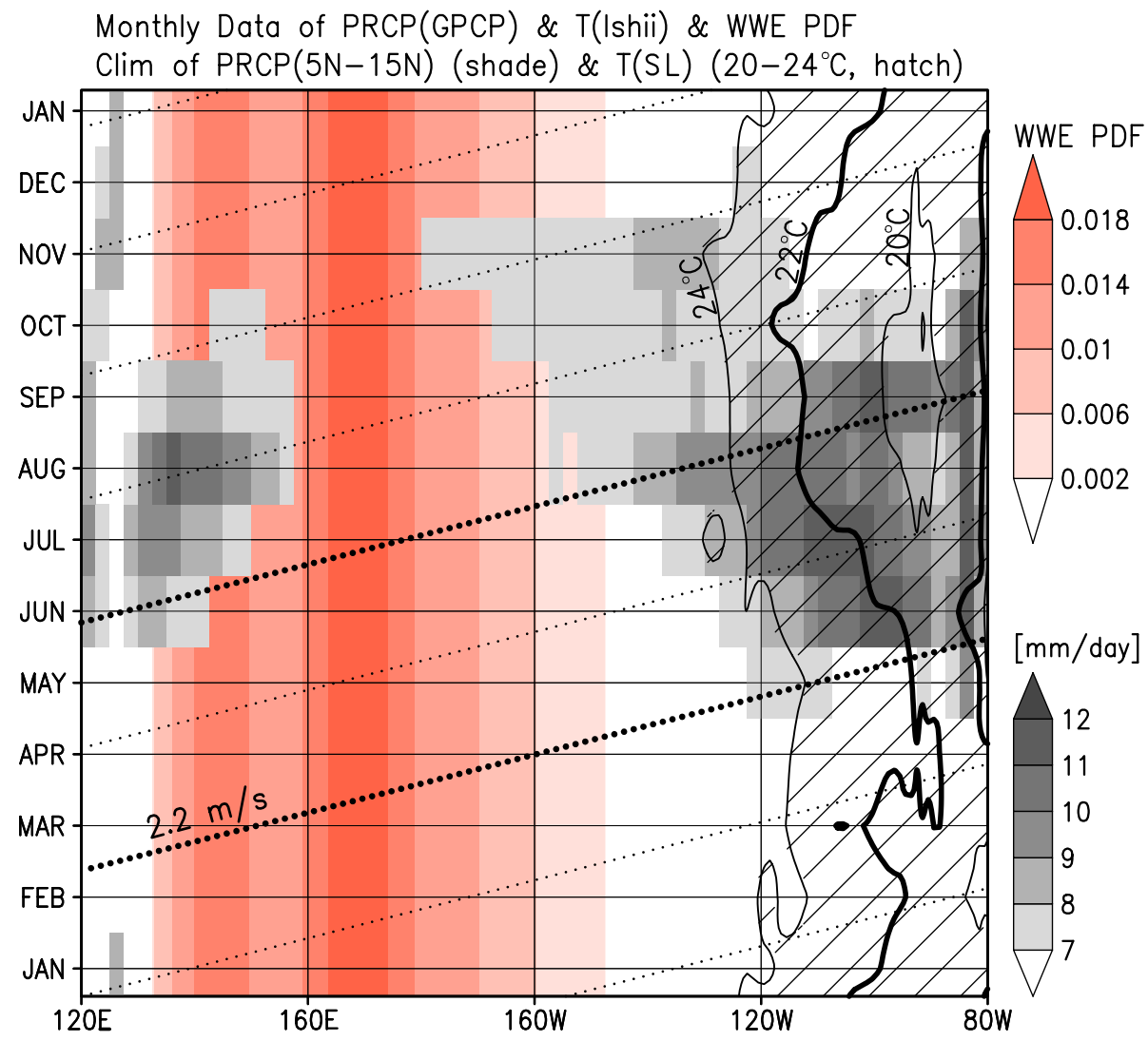

using observational data sets and CGCMs that have more accurate background states.

Past studies indicate that the relationship between WWEs and warming in the eastern Pacific is similar to that shown in our results. An example indicating the importance of timing of WWEs is "a curious case of the El Niño predicted for 2014" (McPhaden et al. 2015). Menkes et al. (2014) suggested that the major difference in El Niños in 2014/15 and the El Niño in 1997/98 is the absence of sequential WWEs after April (see also, Hu and Fedorov 2016), implying the importance of WWEs in May in triggering El Niño. Two WWEs during the period January to March in 2014 might result in the warming in the Niño1+2 region in June and July 2014. It is interesting that a modulation of the climatological seasonality at the equatorial Pacific in a CGCM resulted in a successful forecast of the Niño3.4 SSTA starting from April 2014 (Masuda et al. 2015), implying the importance of the realistic background seasonality on the response to WWEs. In addition to the case in 2014/15, the evolution of the SSTA in 1974/75 is also curious as McPhaden et al. (2015) pointed out. Despite the frequent occurrence of WWEs during winter 1974/75, the El Niño predicted for 1975 did not happen, but the easternmost Pacific was warmed instead in April 1975. On the other hand, preceding the large El Niños in 1982/83, 1997/98, and 2015/16, WWEs occurred in May. Another example is the surface warming that occurred in the far eastern Pacific in mid-2012, which had been predicted to develop an El Niño (Su et al. 2014; McPhaden et al. 2015); subsequent WWEs in March and April 2012 might result in warming. Although the results in Sect. 3 are derived with near-neutral initial values and therefore independent of ENSO dynamics, we confirmed in Sect. 5 that WWEs in May similarly warm the Niño3.4 region for cases developing into El Niño.

One limitation of this study is that the WWEs have been prescribed. In reality, the timing and location of WWEs are state dependent, that is, partly controlled by background SST, sea level pressure, and low-level zonal wind (Lengaigne et al. 2003; Yu et al. 2003; Eisenman et al. 2005; Seiki and Takayabu 2007a, b; Sooraj et al. 2009; Miyama and Hasegawa 2014; Hayashi and Watanabe 2016). Generally, WWEs frequently appear over the western Pacific warm pool, and their timing is partly determined by atmospheric intraseasonal phenomena such as the MJO (Puy et al. 2015), although the statistical relationship between the WWEs and MJO is not very significant in previous studies (Seiki and Takayabu 2007a; Chiodi et al. 2014). The eastern edge of the warm pool is usually located to the west of the dateline, while it extends eastward during or just before an El Niño event. Based on the findings of Seiki and Takayabu (2007a), WWEs often occur near the 
dateline between April and July before El Niño events, consistent with the favorable WWEs that we suggested. Further study is needed to clarify why the timing and location are restricted in the preferable season and longitude prior to El Niño events. A model bias in the background seasonality in the western Pacific, which might result in underestimating the coupled atmosphere-ocean processes at the warm pool edge to warm the western Pacific (e.g., Lengaigne et al. 2003, 2004; Vecchi et al. 2006), is another limitation in this study. The relationship between the response to WWEs and the seasonality in the Pacific warm pool is the subject of future study.

The importance of state-dependent WWEs in producing the spring predictability barrier, i.e., a rapid decrease in ENSO forecast skill during boreal spring (e.g., Torrence and Webster 1998), has been suggested using a CGCM with a statistical WWE parameterization (Lopez and Kirtman 2014) and a conceptual ENSO model with a state-dependent noise (Levine and McPhaden 2015). As shown in Fig. 4a, the Niño3.4 SSTA following a single WWE imposed in January and March is largely scattered after July, while a WWE in May and July tends to warm the Niño3.4 SST with a relatively smaller spread among ensemble members until boreal winter through the robust interaction with the background seasonality at the eastern equatorial Pacific. This suggests that it is less predictable how the coupled atmosphere-ocean system responds to WWEs that appear during the boreal winter and early spring. Although Levine and McPhaden (2015) indicated that the forecast skill in boreal spring is insensitive to a purely stochastic noise in their model, it is possible that the less predictable role of a WWE in January-March in triggering El Niño may produce or enhance the spring barrier under the spatio-temporally realistic basic state even without the state dependence of WWEs.

\section{Conclusions}

The response of an atmosphere-ocean coupled system to WWEs was investigated using a CGCM, focusing on the importance of background seasonality at the eastern equatorial Pacific. Twelve ensemble sets of experiments initialized with ocean states close to neutral to ENSO indicate that WWEs imposed in May efficiently increase Niño3.4 SSTA, independent of the ENSO dynamics. The following three key processes were found to be responsible for Niño3.4 warming: (1) linear zonal advection resulting from an eastward surface current anomaly associated with a WWE-forced oceanic Kelvin wave; (2) the outcropping of subsurface warm water in Niño3.4 region caused by the steeper background thermocline slope; and (3) the reduction of poleward surface current in the northern off-equator due to the southward shift of the background ITCZ interacted with the positive Niño3.4 SSTA originating from (1) and (2). As the background seasonal march of the oceanic and atmospheric conditions is essential for (2) and (3), the timings of WWEs, rather than their locations, are crucial to the warming the Niño3.4 region. From observation-based data sets, we suggest a preferable set of timings and locations of a WWE that maximizes the role for triggering El Niño in the subsequent winter, indicating the importance of WWEs in May. The representativeness of the results for the real world needs to be further investigated.

The impact of WWEs in May on the ENSO cycle was also investigated using the same method as mentioned above, except that the initial values included ENSO fluctuations. For moderate warm cases like El Niño, the imposed WWE affects the system similar to neutral cases. On the other hand, the effect of the WWE is not significant in cold cases such as La Niña. This asymmetry originates from the precipitation activity in the ITCZ, which is more (less) active in warm (cold) cases. Although the ITCZ cannot interact with the warmer SSTA induced by the WWE in cold cases, there is the interaction between them in moderate warm cases, similar to the neutral cases. Because, in nature, the strength of zonal wind is skewed positively over the western equatorial Pacific (e.g., Hayashi and Watanabe 2016), the WWE is a candidate for the phenomena that generate the asymmetry of the ENSO.

The coupled atmosphere-ocean response to the WWEs can vary when the interaction with background seasonality is considered. In addition, the warm water volume in the equatorial Pacific affects the importance of WWEs on the ENSO cycle (Perigaud and Cassou 2000; Lian et al. 2014; Hu et al. 2014; Fedorov et al. 2015), while the state dependence of the atmospheric noise can influence the ENSO asymmetry (Gebbie et al. 2007; Lopez et al. 2013). These indicate that tropical atmospheric disturbances such as WWEs contribute to the diversity of ENSO events (Capotondi et al. 2015). Furthermore, there is a possibility that the biases of atmospheric disturbances and background seasonality in CGCMs result in errors of a modeled ENSO. The relationship between the WWEs and ENSO in CGCMs, for instance, used for CMIP5 may give us insights into the role of WWEs in the coupled system.

Acknowledgements This work was supported by JSPS Grantsin-Aid for Scientific Research 26247079 and 25-5379, and the Program for Risk Information on Climate Change from the Ministry of Education, Culture, Sports, Science and Technology (MEXT), Japan. We are grateful to K. Oogochi, H. Tatebe, T. Suzuki, and other members of the MIROC development term for kindly providing the model sources and tools to analyze the model outputs. We also would like to thank S. Minobe, M. Kimoto, M. Lengaigne, B. Kirtman, and an anonymous reviewer for their advice. GrADS and gnuplot were used to produce the figures. We used GPCP data provided by the NOAA/ 
OAR/ESRL PSD, Boulder, Colorado, USA, from their Web site at http://www.esrl.noaa.gov/psd/.

Open Access This article is distributed under the terms of the Creative Commons Attribution 4.0 International License (http:// creativecommons.org/licenses/by/4.0/), which permits unrestricted use, distribution, and reproduction in any medium, provided you give appropriate credit to the original author(s) and the source, provide a link to the Creative Commons license, and indicate if changes were made.

\section{Appendix: Event detection and composite structure of WWEs}

WWEs are detected following the method of Seiki and Takayabu (2007a) basically to confirm the typical properties of observed and modeled WWEs. For observed WWEs, we use the daily averaged zonal and meridional momentum fluxes of the Japanese Re-Analysis 55 Years (JRA-55, Kobayashi et al. 2015) from 1 January 1958 to 31 March 2014. The spatial resolution is $1.25^{\circ}$ by $1.25^{\circ}$ horizontal grids. The background data is derived by applying a 21-day running mean to averaged values for 30 years from 1981 to 2010 twice to ensure smoothness. A daily anomaly is defined as a departure from the background data. For modeled WWEs, a 100-year output of the model with a pre-industrial radiative forcing is used with a similar manner to the observed WWEs. Note that the positive zonal

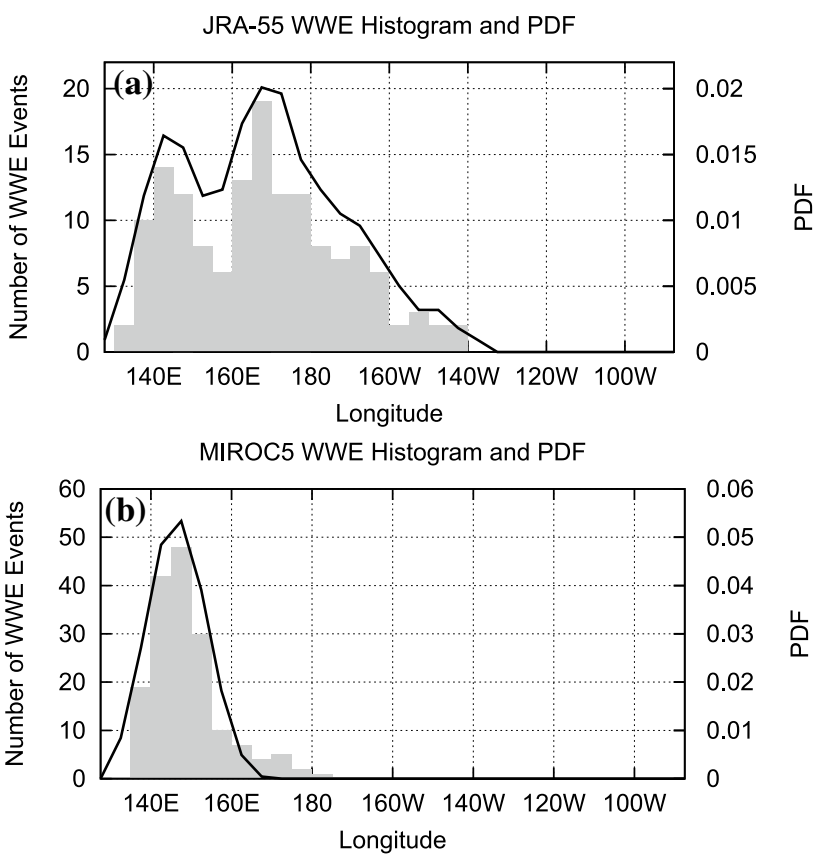

Fig. 16 Histogram for the number of WWEs in the a observation and b model at every $5^{\circ}$ of longitude over the Pacific (gray bars) and the probability density function (solid line)

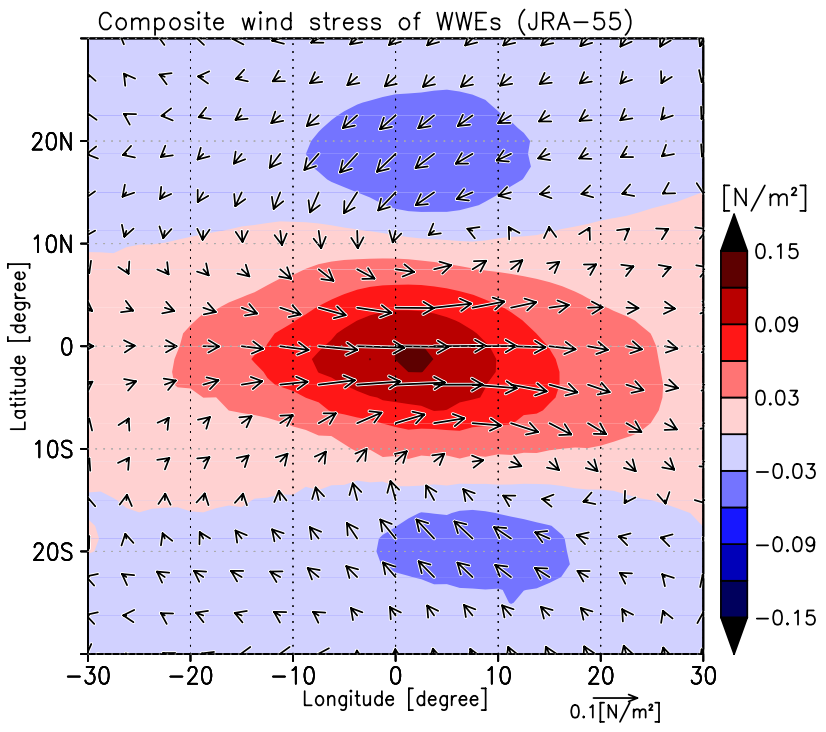

Fig. 17 Horizontal structure of composited WWE in the observation. The vector and color indicate the wind stress anomaly and its zonal component, respectively

and meridional momentum fluxes correspond to westerly and southerly wind stresses.

Following the method of Seiki and Takayabu (2007a) basically, the conditions for detecting WWE events are as follows: The 7-day running averaged zonal momentum flux anomaly averaged between $3^{\circ} \mathrm{S}-3^{\circ} \mathrm{N}$ is larger than $0.07 \mathrm{~N} \mathrm{~m}^{-2}$ zonally, extending at least $10^{\circ}$ in longitude and lasting for at least 2 days. Figure 16 shows histograms of the number of observed and modeled WWE occurrences for every $5^{\circ}$ in longitude over the equatorial Pacific and its probability density function (PDF) derived by the kernel method using the Epanechnikov kernel (cf. Kimoto and Ghil 1993). The event number is concentrated over the western and central Pacific and it has two peaks for the observed WWEs (Fig. 16a), consistent with Fig. 3 of Seiki and Takayabu (2007a). The PDF for the modeled WWEs is concentrated at the western Pacific (Fig. 16b), affected by a model bias in the cold tongue extending too far to the west.

Using the detected WWE events in the longitudinal bins with at least four samples, we derived composite structures of the observed WWEs for each longitudinal bin centered around the day when the anomaly has its maximum during each event. Then, the composite structures of each bin are constructed, centered in the longitudinal direction, to obtain an averaged structure of WWEs in the equatorial Pacific ignoring the overlap of events, shown in Fig. 17. Note that to confirm the overall structure of WWEs, only data over the ocean are used in compositing, even although the original data exist over the land. 


\section{References}

Adler RF, Huffman GJ, Chang A, Ferraro R, Xie PP, Janowiak J, Rudolf B, Schneider U, Curtis S, Bolvin D, Gruber A, Susskind J, Arkin P, Nelkin E (2003) The version-2 global precipitation climatology project (GPCP) monthly precipitation analysis (1979-present). J Hydrometeor 4:1147-1167

Capotondi A, Wittenberg AT, Newman M, Lorenzo ED, Yu JY, Braconnot P, Cole J, Dewitte B, Giese B, Guilyardi E, Jin FF, Karnauskas K, Kirtman B, Lee T, Schneider N, Xue Y, Yeh SW (2015) Understanding ENSO diversity. Bull Amer Meteorol Soc 96:921-938. doi:10.1175/BAMS-D-13-00117.1

Chen D, Lian T, Fu C, Cane MA, Tang Y, Murtugudde R, Song X, Wu Q, Zhou L (2015) Strong influence of westerly wind bursts on El Niño diversity. Nat Geosci 8:339-345. doi:10.1038/ ngeo2399

Chiodi AM, Harrison DE, Vecchi GA (2014) Subseasonal atmospheric variability and El Niño waveguide warming: Observed effects of the Madden-Julian oscillation and westerly wind events. J Clim 27:3619-3642

Drushka K, Bellenger H, Guilyardi E, Lengaigne M, Vialard J, Madec G (2014) Processes driving intraseasonal displacements of the eastern edge of the warm pool: The contribution of westerly wind events. Clim Dyn. doi:10.1007/s00382-014-2297-z

Eisenman I, Yu L, Tziperman E (2005) Westerly wind bursts: ENSO's tail rather than the dog? J Clim 18:5224-5238

Fedorov AV (2002) The response of the coupled tropical oceanatmosphere to westerly wind bursts. Q J R Meteorol Soc 128:1-23

Fedorov AV, Harper SL, Philander SG, Winter B, Witternberg A (2003) How predictable is El Niño? Bull Am Meteorol Soc 84:911G-919

Fedorov AV, Hu S, Lengaigne M, Guilyardi E (2015) The impact of westerly wind bursts and ocean initial state on the development, and diversity of El Niño events. Clim Dyn 44:1381-1401. doi:10.1007/s00382-014-2126-4

Gebbie G, Eisenman I, Witternberg A, Tziperman E (2007) Modulation of westerly wind bursts by sea surface temperature: A semistochastic feedback for ENSO. J Atmos Sci 64:3281-3295

Giese BS, Harrison DE (1991) Eastern equatorial Pacific response to three composite westerly wind types. J Geophys Res 96:3239-3248

Graham FS, Brown JN, Langlais C, Marsland SJ, Wittenberg AT, Holbrook NJ (2014) Effectiveness of the Bjerknes stability index in representing ocean dynamics. Clim Dyn 43:2399-2414. doi:10.1007/s00382-014-2062-3

Harrison DE, Giese BS (1988) Remote westerly wind forcing of the eastern equatorial Pacific; Some model results. Geophys Res Lett 15:804-807

Harrison DE, Schopf PS (1984) Kelvin-wave-induced anomalous advection and the onset of surface warming in El Niño events. Mon Weather Rev 112:923-933

Harrison DE, Vecchi GA (1997) Westerly wind events in the tropical Pacific, 1986-95. J Clim 10:3131-3156

Hartten LM (1996) Synoptic setting of westerly wind bursts. J Geophys Res 101:16,997-17,019

Hayashi M, Watanabe M (2016) Asymmetry between westerly and easterly wind events: Observational evidence. SOLA 12:42-45. doi:10.2151/sola.2016-009

Hendon HH, Wheeler MC, Zhang C (2007) Seasonal dependence of the MJO-ENSO relationship. J Clim 20:531-543

Horel JD (1982) On the annual cycle of the tropical Pacific atmosphere and ocean. Mon Weather Rev 110:1863-1878

Hu S, Fedorov AV (2016) Exceptionally strong easterly wind burst stalling El Niño of 2014. PNAS. doi:10.1073/pnas.1514182113
Hu S, Fedorov AV, Lengaigne M, Guilyardi E (2014) The impact of westerly wind bursts on the diversity and predictability of El Niño events: An ocean energetics perspective. Geophys Res Lett 41:4654-4663. doi:10.1002/2014GL059573

Ishii M, Kimoto M (2009) Reevaluation of historical ocean heat content variations with time-varying XBT and MBT depth bias corrections. J Oceanogr 65:287-299

Jin FF, An SI, Timmermann A, Zhao J (2003) Strong El Niño events and nonlinear dynamical heating. Geophys Res Lett 30:1120. doi:10.1029/2002GL016356

Jin FF, Lin L, Timmermann A, Zhao J (2007) Ensemble-mean dynamics of the ENSO recharge oscillator under state-dependent stochastic forcing. Geophys Res Lett 34(3). doi:10.1029/2 006GL027372

Kessler WS, Kleeman R (2000) Rectification of the Madden-Julian oscillation into the ENSO cycle. J Clim 13:3560-3575

Kimoto M, Ghil M (1993) Multiple flow regimes in the Northern Hemisphere winter. Part I: Methodology and hemispheric regimes. J Atmos Sci 50:2625-2644

Kobayashi S, Ota Y, Ebita A, Moriya M, Onoda H, Onogi K, Kamahori H, Kobayashi C, Endo H, Miyaoka K, Takahashi K (2015) The JRA-55 reanalysis: General specifications and basic characteristics. J Meteorol Soc Japan 93:5-48. doi:10.2151/ jmsj.2015-001

Latif M, Biercamp J, Storch HV (1988) The response of a coupled ocean-atmosphere general circulation model to wind bursts. J Atmos Sci 45:964G-979

Lengaigne M, Boulanger JP, Menkes C, Masson S, Madec G, Delecluse P (2002) Ocean response to the March 1997 westerly wind event. J Geophys Res 107:8015. doi:10.1029/200 1JC000841

Lengaigne M, Boulanger JP, Menkes C, Madec G, Delecluse P, Guilyardi E, Slingo J (2003) The March 1997 westerly wind event and the onset of the 1997/98 El Niño: Understanding the role of the atmospheric response. J Clim 16:3330-3343

Lengaigne M, Guilyardi E, Boulanger JP, Menkes C, Delecluse P, Inness P, Cole J, Slingo J (2004) Triggering of El Niño by westerly wind events in a coupled general circulation model. Clim Dyn 22:601-620. doi:10.1007/s00382-004-0457-2

Levine AFZ, McPhaden M (2015) The annual cycle in ENSO growth rate as a cause of the spring predictability barrier. Geophys Res Lett 42:5034-5041. doi:10.1002/2015GL064309

Lian T, Chen D, Tang Y, Wu Q (2014) Effects of westerly wind bursts on El Niño: A new perspective. Geophys Res Lett 41:35223527. doi:10.1002/2014GL059989

Lopez H, Kirtman BP (2014) WWBs, ENSO predictability, the spring barrier and extreme events. J Geophys Res Atmos 119:10,11410,138. doi:10.1002/2014JD021908

Lopez H, Kirtman BP, Tziperman E, Gebbie G (2013) Impact of interactive westerly wind bursts on CCSM3. Dyn Atmos Ocean 59:24-51. doi:10.1016/j.dynatmoce.2012.11.001

Luther DS, Harrison DE, Knox RA (1983) Zonal winds in the central equatorial Pacific and El Niño. Science 222:327-330

Masuda S, Matthews JP, Ishikawa Y, Mochizuki T, Tanaka Y, Awaji T (2015) A new approach to El Niño prediction beyond the spring season. Sci Rep 5. doi:10.1038/srep16782

McPhaden MJ (1999) Genesis and evolution of the 1997-98 El Niño. Science 283:950-954

McPhaden MJ (2002) Mixed layer temperature balance on intraseasonal timescales in the equatorial Pacific Ocean. J Clim 15:2632-2647

McPhaden MJ, Yu X (1999) Equatorial waves and the 1997-98 El Niño. Geophys Res Lett 26:2961-2964

McPhaden MJ, Timmermann A, Widlansky MJ, Balmaseda MA, Stockdale TN (2015) The curious case of the El Niño that never happened: A perspective from 40 years of progress in climate 
research and forecasting. Bull Am Meteorol Soc 96:1647-1665. doi:10.1175/BAMS-D-14-00089.1

Meinen CS, McPhaden MJ (2000) Observations of warm water volume changes in the equatorial Pacific and their relationship to El Niño and La Niña. J Clim 13:3551-3559

Menkes CE, Lengaigne M, Vialard J, Puy M, Marchesiello P, Cravatte S, Cambon G, (2014) About the role of westerly wind events in the possible development of an El Niño. Geophys Res Lett 41. doi:10.1002/2014GL061186

Miyama T, Hasegawa T (2014) Impact of sea surface temperature on westerlies over the western Pacific warm pool: Case study of an event in 2001/02. SOLA 10:5-9. doi:10.2151/sola.2014-002

Perez CL, Moore AM, Zavala-Garay J, Kleeman R (2005) A comparison of the influence of additive and multiplicative stochastic forcing on a coupled model of ENSO. J Clim 18:5066-5085

Perigaud CM, Cassou C (2000) Importance of oceanic decadal trends and westerly wind bursts for forecasting El Niño. Geophys Res Lett 27:389-392

Puy M, Vialard J, Lengaigne M, Guilyardi E (2015) Modulation of equatorial pacific westerly/easterly wind events by the MaddenJulian oscillation and convectively-coupled Rossby waves. Clim Dyn. doi:10.1007/s00382-015-2695-x

Qiao L, Weisberg RH (1995) Tropical instability wave kinematics: Observations from the Tropical Instability Wave Experiment. J Geophys Res 100:8677-8693

Seiki A, Takayabu YN (2007a) Westerly wind bursts and their relationship with intraseasonal variations and ENSO. Part I: Statistics. Mon Weather Rev 135:3325-3345

Seiki A, Takayabu YN (2007b) Westerly wind bursts and their relationship with intraseasonal variations and ENSO. Part II: Energetics over the western and central Pacific. Mon Weather Rev 135:3346-3361

Sooraj KP, Kim D, Kug JS, Yeh SW, Jin FF, Kang IS (2009) Effects of the low-frequency zonal wind variation on the high frequency atmospheric variability over the tropics. Clim Dyn 33:495-507

Su J, Xiang B, Wang B, Li T (2014) Abrupt termination of the 2012 Pacific warming and its implication on ENSO prediction. Geophys Res Lett 41:9058-9064. doi:10.1002/2014GL062380

Tatebe H, Hasumi H (2010) Formation mechanism of the Pacific equatorial thermocline revealed by a general circulation model with a high accuracy tracer advection scheme. Ocean Model $35: 245-252$

Taylor KE, Stouffer RJ, Meehl GA (2012) An overview of CMIP5 and the experiment design. Bull Am Meteorol Soc 93:485-498

Torrence C, Webster PJ (1998) The annual cycle of persistence in the El Niño/Southern Oscillation. Q J R Meteorol Soc 124:1850-2004

Vecchi GA, Harrison DE (2000) Tropical Pacific sea surface temperature anomalies, El Niño, and equatorial westerly wind events. J Clim 13:1814-1830

Vecchi GA, Wittenberg AT, Rosati A (2006) Reassessing the role of stochastic forcing in the 1997-1998 El Niño. Geophys Res Lett 33:L01,706. doi:10.1029/2005GL024738

Watanabe M, Suzuki T, O'ishi R, Komuro Y, Watanabe S, Emori S, Takemura T, Chikira M, Ogura T, Sekiguchi M, Takata K, Yamazaki D, Yokohata T, Nozawa T, Hasumi H, Tatebe H, Kimoto M, (2010) Improved climate simulation by MIROC5: Mean states, variability, and climate sensitivity. J Climate 23:6312-6335

Watanabe M, Shiogama H, Tatebe H, Hayashi M, Ishii M, Kimoto M (2014) Contribution of natural decadal variability to global warming acceleration and hiatus. Nat Clim Change 4:893-897

Wyrtki K (1975) El Niño-The dynamic response of the equatorial Pacific Ocean to atmospheric forcing. J Phys Oceanogr 5:572-584

Xie SP (1996) Westward propagation of latitudinal asymmetry in a coupled ocean-atmosphere model. J Atmos Sci 53:3236-3250

Xie SP, Philander SGH (1994) A coupled ocean-atmosphere model of relevance to the ITCZ in the eastern Pacific. Tellus A 46:345-350

Yu L, Weller RA, Liu WT (2003) Case analysis of a role of ENSO in regulating the generation of westerly wind bursts in the western equatorial Pacific. J Geophys Res 108(C4):3128. doi:10.1029/20 02JC001498

Zhang T, Sun DZ (2014) ENSO asymmetry in CMIP5 models. J Clim 27:4070-4093

Zhang X, Liu H, Zhang M (2015) Double ITCZ in coupled oceanatmosphere models: From CMIP3 to CMIP5. Geophys Res Lett 42:8651-8659. doi:10.1002/2015GL065973 